\title{
Synthesis and Evaluation of 5-Chloro-2-Methoxy- $N$-(4-Sulphamoylphenyl) Benzamide Derivatives as Anti-cancer Agents
}

\author{
Ahmed M Abdelaziz',2, MingfengYu' ${ }^{1}$, Peng Li ${ }^{1}$, Longjin Zhong ${ }^{1}$, Abdel Nasser B Singab ${ }^{3}$, Atef G Hanna ${ }^{2}$, Khaled A Abouzid ${ }^{3}$, Maged KG \\ Mekhael $^{2}$ and Shudong Wang ${ }^{1 *}$ \\ ${ }^{1}$ Centre for Drug Discovery and Development, Sansom Institute for Health Research and School of Pharmacy and Medical Sciences, University of South Australia, \\ Adelaide, South Australia 5001, Australia \\ ${ }^{2}$ Department of Chemistry of Natural Compounds, National Research Centre, Dokki, 12311, Cairo, Egypt \\ ${ }^{3}$ Faculty of Pharmacy, Ain Shams University, Abbasia, 11566, Cairo, Egypt
}

\begin{abstract}
Sulphonamides embrace a sublime class of drugs with various biological activities. Since the discovery of E7010 in 1992, several sulphonamides as anti-cancer drug candidates have been identified. Herein, a new series of 5-chloro2-methoxy- $N$-(4-sulphamoylphenyl)benzamide derivatives was synthesised, and their anti-proliferative activity was evaluated against human ovarian cancer (A2780) and colon cancer (HCT-116) cell lines. As one of the most potent antiproliferative agents, compound $4 \mathrm{j}$ was further tested against a panel of cancer cell lines revealing that human pancreatic carcinoma (MIA PaCa-2) displayed the highest sensitivity. Cellular mechanistic studies on MIA PaCa-2 cells showed that $4 \mathrm{j}$ arrested the G2/M cell cycle and induced apoptosis.
\end{abstract}



in MIA PaCa-2 pancreatic carcinoma

Keywords: Anti-proliferation; Apoptosis; Structure-activity relationship; Anti-cancer agent; Drug discovery

\section{Introduction}

Sulphonamide bioactive compounds have been developed as antibacteria (e.g. sulphathiazole [1]), diuretics (e.g.furosemide [2]), antidiabetics (e.g. glibenclamide [3,4]), carbonic anhydrase inhibitors (e.g. acetazolamide [5,6]), anti-HIV (e.g. amprenavir [7]), and anti-cancer agents (e.g. E7010 [8]). There is considerable interest in extending and diversifying the sulphonamide framework to further explore therapeutic potentials [9].

Since the discovery of E7010 in 1992 [8], several classes of sulphonamide derivatives have been reported as potential anticancer drug candidates. Those compounds showed different cellular mechanisms such as inhibition of microtubule assembly [10], inhibition of transcription factor NF-Y and matrix metalloproteinase (MMP) [11], and carbonic anhydrase inhibition [12,13]. A series of patents presented novel sulphonamide derivatives targeting protein kinases including vascular endothelial growth factors, platelet-derived growth factors, and c-kit proteins $[14,15]$.

On the other hand, various $N$-(4-sulphamoylphenyl)benzamide containing compounds have demonstrated a range of pharmacological activities including, anti-bacterial [16], inhibition of glucose stimulated insulin release [17], sirtuin-2 deacetylase [18] and viral integrase [19], anti-HIV [20] and other activities that associated with the inhibition of metalloprotease endothelin-converting enzyme and carbonic anhydrase [21-23]. However the anti-cancer potential of the $\mathrm{N}$-(4sulphamoylphenyl)benzamide derivatives has not been fully explored. The reconnaissance of the usefulness and versatility of sulphonamides coupled with the $\mathrm{N}$-(4-sulphamoylphenyl)benzamide scaffold may lead to novel and potent anti-cancer agents. As the different aryl sulphonamides have been shown to act as anti-tumour agents through different mechanisms [24], we prepared a series of sulphonamide derivatives with an $\mathrm{N}$-(4-sulphamoylphenyl)benzamide core and evaluated the anti-cancer activity of these compounds.

\section{Materials and Methods}

\section{Chemistry}

All materials, reagents and solvents were purchased from SigmaAldrich, Alfa Aesar, Merck, GL Biochem, Combi-block or Ajax Finechem, and were used as received. ${ }^{1} \mathrm{H}$ and ${ }^{13} \mathrm{C}$ NMR spectra were recorded at $298 \mathrm{~K}$ on a Bruker AVANCE III 500 spectrometer $\left({ }^{1} \mathrm{H}\right.$ at $500.16 \mathrm{MHz}$ and ${ }^{13} \mathrm{C}$ NMR at $125.76 \mathrm{MHz}$; Faellanden, Switzerland), and were processed using the Bruker Topspin 3.2 software. ${ }^{1} \mathrm{H}$ and ${ }^{13} \mathrm{C}$ NMR spectra are referenced to ${ }^{1} \mathrm{H}$ signals of residual nondeuterated solvents and ${ }^{13} \mathrm{C}$ signals of the deuterated solvents respectively. ${ }^{1} \mathrm{H}$ NMR signals are reported with chemical shift values $\delta(\mathrm{ppm})$, multiplicity ( $\mathrm{s}=$ singlet, $\mathrm{d}=$ doublet, $\mathrm{t}=$ triplet, $\mathrm{q}=$ quartet, $\mathrm{m}=$ multiplet and br=broad), relative integral, coupling constants $J(\mathrm{~Hz})$ and assignments. Mass spectra were recorded on an AB SCIEX TripleTOF 5600 mass spectrometer, and ionisation of all samples was carried out using ESI. Melting points were determined on an Electrothermal IA

*Corresponding author: Shudong Wang, Centre for Drug Discovery and Development, Sansom Institute for Health Research and School of Pharmacy and Medical Sciences, University of South Australia, Adelaide, South Australia 5001, Australia, Tel: +61 88302 2372; Fax: +61 88302 1087; E-mail: shudong.wang@unisa.edu.au

Received May 25, 2015; Accepted June 13, 2015; Published June 15, 2015

Citation: Abdelaziz AM, Yu M, Li P, Zhong L, Singab ANB, et al. (2015) Synthesis and Evaluation of 5-Chloro-2-Methoxy- $N$-(4-Sulphamoylphenyl) Benzamide Derivatives as Anti-cancer Agents. Med chem 5: 253-260. doi:10.4172/2161 0444.1000272

Copyright: (c) 2015 Abdelaziz AM, et al. This is an open-access article distributed under the terms of the Creative Commons Attribution License, which permits unrestricted use, distribution, and reproduction in any medium, provided the original author and source are credited. 
9100 digital melting point apparatus or a Stuart SMP10 melting point apparatus, and are uncorrected. The purity of compounds used for biological evaluation was determined by analytic RP-HPLC which was carried out on a Shimadzu Prominence UFLC system (Ultra Fast Liquid Chromatograph, Kyoto, Japan) equipped with a CBM-20A communications bus module, a DGU-20A5R degassing unit, an LC20AD liquid chromatograph pump, an SIL-20AHT auto-sampler, an SPD-M20A photo diode array detector, a CTO-20A column oven and a Phenomenex Kinetex 5u C18 100A $250 \mathrm{~mm} \times 4.60 \mathrm{~mm}$ column. Method A (gradient $5 \%$ to $95 \% \mathrm{CH}_{3} \mathrm{OH}$ containing $0.1 \%$ FA over 7 $\mathrm{min}$ at a flow rate of $1 \mathrm{~mL} / \mathrm{min}$, followed by $95 \% \mathrm{CH}_{3} \mathrm{OH}$ containing $0.1 \% \mathrm{FA}$ over $13 \mathrm{~min}$ ) and method $\mathrm{B}$ (gradient $5 \%$ to $95 \% \mathrm{CH}_{3} \mathrm{CN}$ containing $0.1 \%$ FA over $7 \mathrm{~min}$ at a flow rate of $1 \mathrm{~mL} / \mathrm{min}$, followed by $95 \% \mathrm{CH}_{3} \mathrm{CN}$ containing $0.1 \% \mathrm{FA}$ over $13 \mathrm{~min}$ ) were used for analytic RP-HPLC. Data acquired from analytic RP-HPLC were processed using LabSolutions Analysis Data System. Analytic TLC was performed on Merck silica gel 60 F254 pre-coated aluminium plates $(0.2 \mathrm{~mm})$ and visualised under UV light $(254 \mathrm{~nm})$. Column chromatography was carried out using a fritted solid loader packed with GRACE Davison DAVISIL's silica gel $60 \AA ̊(40-63 \mu \mathrm{m})$ on a Biotage FlashMaster Personal ${ }^{+}$ flash chromatography system.

5-Chloro-2-methoxy- $N$-phenylbenzamide (2): To a solution of 5-chloro-2-methoxybenzoic acid $(1,10.0 \mathrm{~g}, 53.6 \mathrm{mmol})$ in dichloromethane (DCM, $100 \mathrm{~mL}$ ) at room temperature was added triethylamine $(7.5 \mathrm{~mL}, 53.8 \mathrm{mmol})$ slowly, followed by ethylchloroformate $(5.10 \mathrm{~mL}, 53.8 \mathrm{mmol})$. The reaction mixture was stirred at room temperature for $1 \mathrm{~h}$, and aniline $(4.90 \mathrm{~mL}, 53.8 \mathrm{mmol})$ was added. The reaction mixture was stirred at room temperature for further $2 \mathrm{~h}$, and distilled water $(100 \mathrm{~mL})$ was added. The organic layer was separated, dried over $\mathrm{Na}_{2} \mathrm{SO}_{4}$, and concentrated under reduced pressure. The residue was recrystallised from $\mathrm{MeOH}$ to give 2 as prism crystals (13.2 g, 94\%). ${ }^{1} \mathrm{H}-\mathrm{NMR}$ (DMSO- $\left.d_{6}\right) \delta 3.92\left(\mathrm{~s}, 3 \mathrm{H}, \mathrm{CH}_{3}\right), 7.09$ (t, $1 \mathrm{H}, J=7.4 \mathrm{~Hz}, \mathrm{Ar}-\mathrm{H}), 7.13$ (dd, $1 \mathrm{H}, J=8.2$ and $1.8 \mathrm{~Hz}, \mathrm{Ar}-\mathrm{H}), 7.27$ (d, $1 \mathrm{H}, J=1.8 \mathrm{~Hz}, \mathrm{Ar}-\mathrm{H}), 7.34$ (t, $2 \mathrm{H}, J=7.9 \mathrm{~Hz}, \mathrm{Ar}-\mathrm{H}), 7.63$ (d, $1 \mathrm{H}, J=8.2$ $\mathrm{Hz}, \mathrm{Ar}-\mathrm{H}$ ), 7.72 (d, 2H, J=7.7 Hz, Ar-H), 10.13 (br, s, 1H, NH). MS (ESI) $m / z[\mathrm{M}+\mathrm{H}]^{+}$calcd. for $\mathrm{C}_{14} \mathrm{H}_{13} \mathrm{ClNO}_{2}{ }^{+} 262.0629$ found 262.0578 .

4-(5-Chloro-2-methoxybenzamido)benzenesulphonyl chloride (3): 5-chloro-2-methoxy- $N$-phenylbenzamide (2, $10 \mathrm{~g}, 38 \mathrm{mmol})$ was treated with chlorosulphonic acid $(50 \mathrm{~mL})$ on an ice bath with continuous stirring, then removed from the ice bath and stirring was continued at room temperature for 12 hours. The reaction mixture was added on ice slowly to afford white precipitate. The precipitate was filtered and washed with distilled water and recrystallised from DCM to afford white needle crystals $(12 \mathrm{~g}, 87 \%) .{ }^{1} \mathrm{H} \mathrm{NMR}\left(\mathrm{CDCl}_{3}, 500 \mathrm{MHz}\right)$ $\delta 4.11\left(\mathrm{~s}, 3 \mathrm{H}, \mathrm{CH}_{3}\right), 7.02(\mathrm{~d}, 1 \mathrm{H}, J=8.8 \mathrm{~Hz}, \mathrm{Ar}-\mathrm{H}), 7.50$ (dd, $1 \mathrm{H}, J=8.8$ and $2.7 \mathrm{~Hz}, \mathrm{Ar}-\mathrm{H}), 7.91$ (d, 2H, J=8.9 Hz, $2 \mathrm{Ar}-\mathrm{H}), 8.02$ (d, 2H, J=8.9 $\mathrm{Hz}, 2 \mathrm{Ar}-\mathrm{H}), 8.24$ (d, $1 \mathrm{H}, J=2.7 \mathrm{~Hz}, \mathrm{Ar}-\mathrm{H}), 10.11$ (br s, $1 \mathrm{H}, \mathrm{NH})$. MS (ESI) $m / z[\mathrm{M}+\mathrm{H}]^{+}$calcd. for $\mathrm{C}_{14} \mathrm{H}_{12} \mathrm{Cl}_{2} \mathrm{NO}_{4} \mathrm{~S}^{+} 359.9858$ found 359.9597

General synthetic procedure of 5-chloro-2-methoxy- $N-(4$ sulphamoylphenyl)benzamide derivatives (4a-t): To a solution of 4-(5-chloro-2-methoxybenzamido)benzenesulphonyl chloride (3, $0.25 \mathrm{~g}, 0.69 \mathrm{mmol})$ in tetrahydrofuran (THF) $(10 \mathrm{~mL})$ and sodium carbonate $(0.73 \mathrm{~g}, 0.69 \mathrm{mmol})$ in water $(5 \mathrm{~mL})$ was added appropriate amine $(1.05 \mathrm{mmol})$. The mixture was stirred for 24 hours at room temperature. The tetrahydrofuran was evaporated under vacuum, followed by acidification using $1 \mathrm{~N} \mathrm{HCl}$. The precipitate formed was washed with water and purified by Biotage ${ }^{\circ}$ Flash Master Personal ${ }^{+}$flash chromatography (silica gel, petroleum benzene ramping to petroleum benzene:ethyl acetate $=60: 40$ unless otherwise stated) to give the desired compound. 5-chloro-2-methoxy- $N$-(4-( $N$-phenylsulphamoyl $)$ phenyl $)$ benzamide (4a): White crystalline solid, yield: $75 \%$. mp: $202-204^{\circ} \mathrm{C}$. ${ }^{1} \mathrm{H}-\mathrm{NMR}\left(\mathrm{DMSO}-d_{6}\right): \delta 3.85\left(\mathrm{~s}, 3 \mathrm{H}, \mathrm{CH}_{3}\right), 7.02(\mathrm{t}, 1 \mathrm{H}, J=7.4 \mathrm{~Hz}, \mathrm{Ar}-\mathrm{H})$, 7.09 (d, 2H, $J=7.6 \mathrm{~Hz}$, Ar-H), 7.20 (d, $1 \mathrm{H}, J=8.8 \mathrm{~Hz}, \mathrm{Ar}-\mathrm{H}), 7.23$ (t, $2 \mathrm{H}$, $J=7.4 \mathrm{~Hz}, \mathrm{Ar}-\mathrm{H}), 7.55$ (dd, $1 \mathrm{H}, J=8.8$ and $2.7 \mathrm{~Hz}, \mathrm{Ar}-\mathrm{H}), 7.57$ (d, $2 \mathrm{H}$, $J=8.8 \mathrm{~Hz}, \mathrm{Ar}-\mathrm{H}), 7.72(\mathrm{~d}, 2 \mathrm{H}, J=8.8 \mathrm{~Hz}, \mathrm{Ar}-\mathrm{H}), 7.83(\mathrm{~d}, 2 \mathrm{H}, J=8.8 \mathrm{~Hz}$, Ar-H), 10.19 (br s, $1 \mathrm{H}, \mathrm{NH}), 10.54$ (br s, $1 \mathrm{H}, \mathrm{NH}) .{ }^{13} \mathrm{C}-\mathrm{NMR}\left(\mathrm{CDCl}_{3}\right)$ : 856.9, 113.3, 120.1, 122.1, 122.6, 125.8, 127.6, 128.8, 129.6, 132.5, 133.6, 134.0, 136.5, 142.5, 155.8, 162.3. MS (ESI) $\mathrm{m} / z$ [M-H] ${ }^{-}$calcd. for $\mathrm{C}_{20} \mathrm{H}_{16} \mathrm{ClN}_{2} \mathrm{O}_{4} \mathrm{~S}^{-} 415.0525$ found 415.0665. Anal. RP-HPLC Method A: $t \mathrm{R} 12.02 \mathrm{~min}$, purity $>99 \%$; Method B: $t \mathrm{R} 11.53 \mathrm{~min}$, purity $>99 \%$.

5-chloro-2-methoxy- $N$-(4-( $N$-(m-tolyl) sulphamoyl)phenyl) benzamide (4b): White crystalline solid, yield: $72 \%$. mp: $201-203^{\circ} \mathrm{C}$. $1 \mathrm{H} \mathrm{NMR}{ }^{1} \mathrm{H}-\mathrm{NMR}\left(\mathrm{CDCl}_{3}\right): \delta 2.52\left(\mathrm{~s}, 3 \mathrm{H}, \mathrm{CH}_{3}\right), 4.30\left(\mathrm{~s}, 3 \mathrm{H}, \mathrm{CH}_{3}\right)$, 6.82 (br s, $1 \mathrm{H}, \mathrm{NH}), 7.11(\mathrm{~d}, 1 \mathrm{H}, J=8.3 \mathrm{~Hz}, \mathrm{Ar}-\mathrm{H}), 7.17(\mathrm{~d}, 2 \mathrm{H}, J=8.7$ $\mathrm{Hz}, \operatorname{Ar}-\mathrm{H}), 7.23$ (d, $1 \mathrm{H}, J=8.9 \mathrm{~Hz}, \mathrm{Ar}-\mathrm{H}), 7.35(\mathrm{t}, 1 \mathrm{H}, J=7.7 \mathrm{~Hz}, \mathrm{Ar}-\mathrm{H})$, $7.71(\mathrm{dd}, 1 \mathrm{H}, J=8.8$ and $2.7 \mathrm{~Hz}, \mathrm{Ar}-\mathrm{H}), 7.95(\mathrm{~d}, 1 \mathrm{H}, J=2.7 \mathrm{~Hz}, \mathrm{Ar}-\mathrm{H})$, $7.97(\mathrm{~d}, 2 \mathrm{H}, J=8.7 \mathrm{~Hz}, \mathrm{Ar}-\mathrm{H}), 8.0(\mathrm{~d}, 2 \mathrm{H}, J=8.7 \mathrm{~Hz}, \mathrm{Ar}-\mathrm{H}), 8.46(\mathrm{~d}, 1 \mathrm{H}$, $J=2.7 \mathrm{~Hz}, \mathrm{Ar}-\mathrm{H}), 10.17$ (br s, $1 \mathrm{H}, \mathrm{NH}) .{ }^{13} \mathrm{C}-\mathrm{NMR}\left(\mathrm{CDCl}_{3}\right): \delta 21.5,57.0$, $113.3,118.8,120.9,122.5,122.6,126.5,127.6,128.8,129.3,132.5,133.6$, $134.1,136.4,139.6,142.4,155.9,162.4$. MS (ESI) $m / z$ [M-H] ${ }^{-}$calcd. for $\mathrm{C}_{21} \mathrm{H}_{18} \mathrm{ClN}_{2} \mathrm{O}_{4} \mathrm{~S}^{-} 429.0681$ found 429.0827. Anal. RP-HPLC Method A: $t \mathrm{R} 12.26 \mathrm{~min}$, purity $>97 \%$; Method $\mathrm{B}$ : $t \mathrm{R} 11.80 \mathrm{~min}$, purity $>97 \%$.

5-chloro-2-methoxy- $N$-(4-( $N$-(p-tolyl)sulphamoyl)phenyl) benzamide (4c): White powder, yield: $72 \%$. mp: $140-142^{\circ} \mathrm{C} .{ }^{1} \mathrm{H}-\mathrm{NMR}$ $\left(\right.$ DMSO- $\left.d_{6}\right): \delta 2.18\left(\mathrm{~s}, 3 \mathrm{H}, \mathrm{CH}_{3}\right), 3.85\left(\mathrm{~s}, 3 \mathrm{H}, \mathrm{CH}_{3}\right), 6.97(\mathrm{~d}, 2 \mathrm{H}, J=8.5 \mathrm{~Hz}$, Ar-H), 7.03 (d, $2 \mathrm{H}, J=8.5 \mathrm{~Hz}, \mathrm{Ar}-\mathrm{H}$ ), 7.20 (d, 1H, J=8.8 Hz, Ar-H), 7.55 (dd, $1 \mathrm{H}, J=8.8$ and $2.7 \mathrm{~Hz}, \mathrm{Ar}-\mathrm{H}$ ), 7.57 (d, $1 \mathrm{H}, J=2.7 \mathrm{~Hz}, \mathrm{Ar}-\mathrm{H}$ ), 7.69 (d, $2 \mathrm{H}, J=8.8 \mathrm{~Hz}, \mathrm{Ar}-\mathrm{H}), 7.82$ (d, $2 \mathrm{H}, J=8.8 \mathrm{~Hz}, \mathrm{Ar}-\mathrm{H}), 10.03$ (br s, $1 \mathrm{H}$, $\mathrm{NH}), 10.54$ (br s, $1 \mathrm{H}, \mathrm{NH}) .{ }^{13} \mathrm{C}-\mathrm{NMR}$ (DMSO- $d_{6}$ ): $\delta 20.3,56.3,114.0$, $119.4,120.6,124.2,126.7,127.9,128.7,129.6,131.5,133.3,133.7,135.1$, 142.6, 155.3, 163.9. MS (ESI) $m / z[\mathrm{M}-\mathrm{H}]^{-}$calcd. for $\mathrm{C}_{21} \mathrm{H}_{18} \mathrm{ClN}_{2} \mathrm{O}_{4} \mathrm{~S}$ 429.0754 found 429.0772. Anal. RP-HPLC Method A: $t \mathrm{R} 12.17 \mathrm{~min}$, purity $>99 \%$; Method B: $t$ R 11.80 min, purity $>99 \%$.

5-chloro- $N$-(4-( $N$-(2-ethylphenyl) sulphamoyl) phenyl)-2methoxybenzamide (4d): White crystalline solid, yield: $45 \%$. mp: 189$191^{\circ} \mathrm{C} .{ }^{1} \mathrm{H}-\mathrm{NMR}$ (DMSO- $d_{6}$ ): $\delta 1.18(\mathrm{t}, 3 \mathrm{H}, J=7.6 \mathrm{~Hz}, \mathrm{CH} 3), 2.58(\mathrm{q}, 2 \mathrm{H}$, $J=7.6 \mathrm{~Hz}, \mathrm{CH} 2), 4.06$ (s, 3H, CH3), 6.50 (br s, $1 \mathrm{H}, \mathrm{NH}), 6.99$ (d, $1 \mathrm{H}$, $J=8.2 \mathrm{~Hz}, \mathrm{Ar}-\mathrm{H}), 7.15(\mathrm{t}, 1 \mathrm{H}, J=7.8 \mathrm{~Hz}, \mathrm{Ar}-\mathrm{H}), 7.24(\mathrm{~d}, 1 \mathrm{H}, J=8.9 \mathrm{~Hz}$, Ar-H), 7.29 (t, $1 \mathrm{H}, J=7.9 \mathrm{~Hz}, \operatorname{Ar}-\mathrm{H}), 7.71(\mathrm{dd}, 1 \mathrm{H}, J=8.8$ and $2.7 \mathrm{~Hz}$, Ar-H), 7.79 (d, 1H, J=7.9 Hz, Ar-H) 7.94 (d, 2H, J=8.8 Hz, Ar-H), 8.00 (d, $2 \mathrm{H}, J=8.8 \mathrm{~Hz}, \mathrm{Ar}-\mathrm{H}), 8.47$ (d, $1 \mathrm{H}, J=2.7 \mathrm{~Hz}, \mathrm{Ar}-\mathrm{H}), 10.15$ (br s, $1 \mathrm{H}$, $\mathrm{NH}) .{ }^{1} \mathrm{H}-\mathrm{NMR}\left(\mathrm{DMSO}-d_{6}\right): \delta 15.4,28.2,56.8,111.0,113.5,120.0,121.6$, $122.9,126.0,126.5,128.1,129.0132 .3,133.8,133.9,134.5,142.6,149.8$, 156.3, 162.4. MS (ESI) $\mathrm{m} / z$ [M-H $]^{-}$calcd. for $\mathrm{C}_{22} \mathrm{H}_{20} \mathrm{ClN}_{2} \mathrm{O}_{4} \mathrm{~S}^{-} 443.0838$ found 443.1058. Anal. RP-HPLC Method A: $t \mathrm{R} 12.42 \mathrm{~min}$, purity $>99 \%$; Method B: $t \mathrm{R} 12.11 \mathrm{~min}$, purity $>99 \%$.

5-chloro- $N$-(4-( $N$-(4-ethylphenyl) sulphamoyl)phenyl)-2methoxybenzamide (4e): White crystalline solid, yield: 64\%. mp: 181$183^{\circ} \mathrm{C} .{ }^{1} \mathrm{H}-\mathrm{NMR}$ (DMSO- $\left.d_{6}\right): \delta 1.10\left(\mathrm{t}, 3 \mathrm{H}, J=7.6 \mathrm{~Hz}, \mathrm{CH}_{3}\right.$ ), $2.48(\mathrm{q}, 2 \mathrm{H}$, $J=7.6 \mathrm{~Hz}, \mathrm{CH} 2), 3.85$ (s, 3H, $\left.\mathrm{CH}_{3}\right) 6.99$ (d, 2H, J=8.5 Hz, Ar-H), 7.06 (d, $2 \mathrm{H}, J=8.5 \mathrm{~Hz}, \mathrm{Ar}-\mathrm{H}$ ), 7.20 (d, $1 \mathrm{H}, J=8.8 \mathrm{~Hz}, \mathrm{Ar}-\mathrm{H}$ ), 7.55 (dd, $1 \mathrm{H}, J=8.8$ and $2.7 \mathrm{~Hz}, \operatorname{Ar}-\mathrm{H}), 7.57(\mathrm{~d}, 1 \mathrm{H}, J=2.7 \mathrm{~Hz}, \operatorname{Ar}-\mathrm{H}), 7.71(\mathrm{~d}, 2 \mathrm{H}, J=8.8$ $\mathrm{Hz}, \mathrm{Ar}-\mathrm{H}$ ), 7.83 (d, 2H, J=8.8 Hz, Ar-H), 10.07 (br s, $1 \mathrm{H}, \mathrm{NH}$ ), 10.55 (br s, $1 \mathrm{H}, \mathrm{NH}) .{ }^{13} \mathrm{C}-\mathrm{NMR}$ (DMSO- $\left.d_{6}\right): \delta 15.5,27.5,56.4,114.1,119.4$, $120.6,124.3,126.7,128,128.5,128.8,131.6,133.9,135.4,139.6,142.6$, 155.3, 163.9. MS (ESI) $\mathrm{m} / z$ [M-H $]^{-}$calcd. for $\mathrm{C}_{22} \mathrm{H}_{20} \mathrm{ClN}_{2} \mathrm{O}_{4} \mathrm{~S}^{-} 443.0838$ found 443.0850. Anal. RP-HPLC Method A: $t \mathrm{R} 12.41 \mathrm{~min}$, purity $>99 \%$; Method B: $t \mathrm{R} 12.11 \mathrm{~min}$, purity $>99 \%$. 
5-chloro-2-methoxy- $N$-(4-(N-(2-(trifluoromethyl)phenyl) sulphamoyl)phenyl)benzamide (4f): White powder, yield: $46 \%$. mp: $170-172^{\circ} \mathrm{C} .{ }^{1} \mathrm{H}-\mathrm{NMR}\left(\mathrm{DMSO}-d_{6}\right): \delta 3.84\left(\mathrm{~s}, 3 \mathrm{H}, \mathrm{CH}_{3}\right), 7.20(\mathrm{~d}, 1 \mathrm{H}, J=8.8$ $\mathrm{Hz}, \mathrm{Ar}-\mathrm{H}), 7.36-7.38(\mathrm{~m}, 3 \mathrm{H}, \mathrm{Ar}-\mathrm{H}), 7.48(\mathrm{t}, 1 \mathrm{H}, J=8.0 \mathrm{~Hz}, \mathrm{Ar}-\mathrm{H})$, $7.55(\mathrm{dd}, 1 \mathrm{H}, J=8.8$ and $2.7 \mathrm{~Hz}, \mathrm{Ar}-\mathrm{H}), 7.57(\mathrm{~d}, 1 \mathrm{H}, J=2.7 \mathrm{~Hz}, \mathrm{Ar}-\mathrm{H})$, $7.76(\mathrm{~d}, 2 \mathrm{H}, J=8.8 \mathrm{~Hz}, \mathrm{Ar}-\mathrm{H}), 7.86(\mathrm{~d}, 2 \mathrm{H}, J=8.8 \mathrm{~Hz}, \mathrm{Ar}-\mathrm{H}), 10.58(\mathrm{br}$ s, $1 \mathrm{H}, \mathrm{NH}), 10.69$ (br s, $1 \mathrm{H}, \mathrm{NH}) .{ }^{13} \mathrm{C}-\mathrm{NMR}\left(\mathrm{DMSO}-d_{6}\right): \delta 56.4,114.1$, $115.4,119.6,120.2,123.0,124.9,126.7,128.0,128.7,129.7,130.0,130.7$, 131.6, 133.3, 139.0, 142.9, 155.3, 163.9. MS (ESI) $\mathrm{m} / z$ [M-H] $]^{-}$calcd. for $\mathrm{C}_{21} \mathrm{H}_{15} \mathrm{ClF}_{3} \mathrm{~N}_{2} \mathrm{O}_{4} \mathrm{~S}^{-} 483.0399$ found 483.0507. Anal. RP-HPLC Method A: $t$ R 12.35 min, purity $>99 \%$; Method B: $t \mathrm{R} 12.07 \mathrm{~min}$, purity $>99 \%$.

5-chloro-2-methoxy- $N$-(4-( $N$-(4-(trifluoromethyl)phenyl) sulphamoyl)phenyl)benzamide (4g): White powder, yield: $49 \%$ mp: $173-175^{\circ} \mathrm{C} .{ }^{1} \mathrm{H}-\mathrm{NMR}\left(\mathrm{DMSO}-d_{6}\right): \delta 3.84\left(\mathrm{~s}, 3 \mathrm{H}, \mathrm{CH}_{3}\right), 7.20(\mathrm{~d}, 1 \mathrm{H}, J=8.8$ $\mathrm{Hz}, \mathrm{Ar}-\mathrm{H}), 7.28(\mathrm{~d}, 2 \mathrm{H}, J=8.8 \mathrm{~Hz}, \mathrm{Ar}-\mathrm{H}), 7.55$ (dd, $1 \mathrm{H}, J=8.8$ and 2.7 $\mathrm{Hz}, \mathrm{Ar}-\mathrm{H}), 7.57$ (d, 1H, J=2.7 Hz, Ar-H), 7.60 (d, 2H, J=8.8 Hz, Ar-H), 7.80 (d, $2 \mathrm{H}, J=8.8 \mathrm{~Hz}, \mathrm{Ar}-\mathrm{H}), 7.87$ (d, $2 \mathrm{H}, J=8.8 \mathrm{~Hz}, \mathrm{Ar}-\mathrm{H}), 10.59$ (br s, $1 \mathrm{H}, \mathrm{NH}), 10.83$ (br s, $1 \mathrm{H}, \mathrm{NH}) .{ }^{13} \mathrm{C}-\mathrm{NMR}$ (DMSO- $d_{6}$ ): 56.8, 114.5, $119.1,120.0,123.6,124.6,125.8,127.0,127.1,128.5,129.1,132.0$, 143.4, 155.7, 164.4. MS (ESI) $\mathrm{m} / z[\mathrm{M}-\mathrm{H}]^{-}$calcd. for $\mathrm{C}_{21} \mathrm{H}_{15} \mathrm{ClF}_{3} \mathrm{~N}_{2} \mathrm{O}_{4} \mathrm{~S}^{-}$ 483.0399 found 483.0594. Anal. RP-HPLC Method A: $t \mathrm{R} 12.46 \mathrm{~min}$, purity $>99 \%$; Method B: $t \mathrm{R} 12.11 \mathrm{~min}$, purity $>99 \%$.

5-chloro-2-methoxy- $\mathrm{N}$-(4-( $\mathrm{N}$-(2-methoxyphenyl)sulphamoyl) phenyl)benzamide (4h): White powder, yield: $83 \%$. mp: $173-175^{\circ} \mathrm{C}$. ${ }^{1} \mathrm{H}-\mathrm{NMR}\left(\mathrm{CDCl}_{3}\right): \delta 3.91\left(\mathrm{~s}, 3 \mathrm{H}, \mathrm{CH}_{3}\right), 4.30\left(\mathrm{~s}, 3 \mathrm{H}, \mathrm{CH}_{3}\right), 6.99(\mathrm{~d}, 1 \mathrm{H}$, $J=8.2 \mathrm{~Hz}, \mathrm{Ar}-\mathrm{H}), 7.15(\mathrm{t}, 1 \mathrm{H}, J=7.8 \mathrm{~Hz}, \mathrm{Ar}-\mathrm{H}), 7.24(\mathrm{~d}, 1 \mathrm{H}, J=8.9 \mathrm{~Hz}$, Ar-H), 7.26 (br s, $1 \mathrm{H}, \mathrm{NH}$ ), 7.29 (t, $1 \mathrm{H}, J=7.9 \mathrm{~Hz}, \mathrm{Ar}-\mathrm{H}), 7.71$ (dd, $1 \mathrm{H}, J=8.8$ and $2.7 \mathrm{~Hz}, \mathrm{Ar}-\mathrm{H}), 7.79(\mathrm{~d}, 1 \mathrm{H}, J=7.9 \mathrm{~Hz}, \mathrm{Ar}-\mathrm{H}) 7.94(\mathrm{~d}$, $2 \mathrm{H}, J=8.8 \mathrm{~Hz}, \mathrm{Ar}-\mathrm{H}), 8.00$ (d, 2H, J=8.8 Hz, Ar-H), 8.47 (d, 1H, J=2.7 $\mathrm{Hz}, \mathrm{Ar}-\mathrm{H}), 10.15$ (br s, $1 \mathrm{H}, \mathrm{NH}) .{ }^{13} \mathrm{C}-\mathrm{NMR}\left(\mathrm{CDCl}_{3}\right): \delta 55.9,57.0,110.8$, $113.4,119.9,121.3,121.5,122.7,125.7,126.1,127.6,128.8,132.5$, $133.7,134.3,142.3,149.8,155.9,162.4$. MS (ESI) $\mathrm{m} / z$ [M-H $]^{-}$calcd. for $\mathrm{C}_{21} \mathrm{H}_{18} \mathrm{ClN}_{2} \mathrm{O}_{5} \mathrm{~S}^{-} 445.0630$ found 445.0874. Anal. RP-HPLC Method A: $t$ R 11.99 min, purity $>99 \%$; Method B: $t$ R $11.72 \mathrm{~min}$, purity $>99 \%$.

5-chloro-2-methoxy- $\mathrm{N}$-(4-( $\mathrm{N}$-(4-methoxyphenyl)sulphamoyl) phenyl)benzamide (4i): White crystalline solid, yield: $62 \%$. mp: $217-$ $219^{\circ} \mathrm{C} .{ }^{1} \mathrm{H}-\mathrm{NMR}$ (DMSO- $\left.d_{6}\right): \delta 3.67\left(\mathrm{~s}, 3 \mathrm{H}, \mathrm{CH}_{3}\right.$ ), 3.85 (s, $\left.3 \mathrm{H}, \mathrm{CH}_{3}\right), 6.80$ (d, $2 \mathrm{H}, J=9.0 \mathrm{~Hz}, \operatorname{Ar}-\mathrm{H}), 6.98(\mathrm{~d}, 2 \mathrm{H}, J=9.0 \mathrm{~Hz}, \operatorname{Ar}-\mathrm{H}), 7.20(\mathrm{~d}, 1 \mathrm{H}$, $J=8.5 \mathrm{~Hz}, \mathrm{Ar}-\mathrm{H}), 7.55$ (dd, $1 \mathrm{H}, J=8.8$ and $2.7 \mathrm{~Hz}, \mathrm{Ar}-\mathrm{H}), 7.58(\mathrm{~d}, 1 \mathrm{H}$, $J=2.7 \mathrm{~Hz}, \mathrm{Ar}-\mathrm{H}), 7.64$ (d, 2H, $J=8.8 \mathrm{~Hz}, \mathrm{Ar}-\mathrm{H}), 7.82(\mathrm{~d}, 2 \mathrm{H}, J=8.8 \mathrm{~Hz}$, Ar-H), 9.83 (br s, $1 \mathrm{H}, \mathrm{NH}), 10.54$ (br s, $1 \mathrm{H}, \mathrm{NH}) .{ }^{13} \mathrm{C}-\mathrm{NMR}$ (DMSO-d $)$ : 855.2, 56.3, 114.1, 114.3, 119.3, 123.4, 124.2, 126.7, 127.9, 128.7, 130.2, $131.5,133.7,142.5,155.3,156.5,163.9$. MS (ESI) $m / z$ [M-H] ${ }^{-}$calcd. for $\mathrm{C}_{21} \mathrm{H}_{18} \mathrm{ClN}_{2} \mathrm{O}_{5} \mathrm{~S}^{-} 445.0630$ found 445.0757. Anal. RP-HPLC Method A: $t \mathrm{R} 11.85 \mathrm{~min}$, purity $>98 \%$; Method B: $t \mathrm{R} 11.43 \mathrm{~min}$, purity $>98 \%$.

5-chloro- $N$-(4-( $N$-(4-fluorophenyl) sulphamoyl)phenyl)-2methoxybenzamide (4j): White powder, yield: $45 \%$. mp: $197-199^{\circ} \mathrm{C}$. ${ }^{1} \mathrm{H}-\mathrm{NMR}$ (DMSO-d) $\delta 3.85\left(\mathrm{~s}, 3 \mathrm{H}, \mathrm{CH}_{3}\right.$ ), $7.08(\mathrm{~d}, 4 \mathrm{H}, J=6.6 \mathrm{~Hz}, \mathrm{Ar}-$ $\mathrm{H}), 7.20$ (d, $1 \mathrm{H}, J=8.8 \mathrm{~Hz}, \mathrm{Ar}-\mathrm{H}), 7.55(\mathrm{dd}, 1 \mathrm{H}, J=8.8$ and $2.7 \mathrm{~Hz}, \mathrm{Ar}-$ H), 7.53 (d, 1H, J=2.7 Hz, Ar-H), 7.67 (d, 2H, J=8.8 Hz, Ar-H), 7.67 (d, 2H, J=8.8 Hz, Ar-H), 10.15 (br s, $1 \mathrm{H}, \mathrm{NH}$ ), 10.56 (br s, 1H, NH). ${ }^{13} \mathrm{C}-\mathrm{NMR}\left(\mathrm{DMSO}-d_{6}\right): \delta 56.4,114.1,115.9,119.4,122.8,124.3,124.3$, $126.7,127.9,128.8,131.6,133.5,134.1,142.7,155.3,164.0$. MS (ESI) $\mathrm{m} / z[\mathrm{M}-\mathrm{H}]^{-}$calcd. for $\mathrm{C}_{20} \mathrm{H}_{15} \mathrm{ClFN}_{2} \mathrm{O}_{4} \mathrm{~S}^{-} 433.0431$ found 433.0430 . Anal. RP-HPLC Method A: $t \mathrm{R} 12.02$ min, purity $>96 \%$; Method B: $t \mathrm{R}$ $11.59 \mathrm{~min}$, purity $>98 \%$.

5-chloro- $N$-(4-( $N$-(5-fluoro-2-methylphenyl)sulphamoyl) phenyl)-2-methoxybenzamide (4K): White powder, yield: $52 \%$. mp:
185-187 ${ }^{\circ} \mathrm{C} .{ }^{1} \mathrm{H}-\mathrm{NMR}\left(\mathrm{CDCl}_{3}\right): \delta 2.03\left(\mathrm{~s}, 3 \mathrm{H}, \mathrm{CH}_{3}\right), 4.09\left(\mathrm{~s}, 3 \mathrm{H}, \mathrm{CH}_{3}\right)$, 6.27 (br s, 1H, NH), $6.84(\mathrm{~d}, 1 \mathrm{H}, J=9.4 \mathrm{~Hz}, \mathrm{Ar}-\mathrm{H}), 6.87(\mathrm{~d}, 1 \mathrm{H}, J=2.8 \mathrm{~Hz}$ Ar-H), 7.01 (d, $1 \mathrm{H}, J=8.9 \mathrm{~Hz}, \mathrm{Ar}-\mathrm{H})$ 7.21-7.24 (m, 1H, Ar-H), 7.49 (dd, $1 \mathrm{H}, J=8.8$ and $2.7 \mathrm{~Hz}, \mathrm{Ar}-\mathrm{H}), 7.69(\mathrm{~d}, 2 \mathrm{H}, J=8.8 \mathrm{~Hz}, \mathrm{Ar}-\mathrm{H}), 7.77(\mathrm{~d}, 2 \mathrm{H}$, $J=8.8 \mathrm{~Hz}, \mathrm{Ar}-\mathrm{H}), 8.25(\mathrm{~d}, 1 \mathrm{H}, J=2.7 \mathrm{~Hz}, \mathrm{Ar}-\mathrm{H}), 10.00$ (br s, $1 \mathrm{H}, \mathrm{NH})$ ${ }^{13} \mathrm{C}-\mathrm{NMR}\left(\mathrm{CDCl}_{3}\right): \delta 18.1,57.0,113.4,113.9,117.5,120.1,122.6,127.6$, 127.9 128.0, 128.7, 130.2, 132.5, 133.7, 134.4, 135.8, 155.9, 160.2, 162.4 MS (ESI) $m / z[\mathrm{M}-\mathrm{H}]^{-}$calcd. $\mathrm{C}_{21} \mathrm{H}_{17} \mathrm{ClFN}_{2} \mathrm{O}_{4} \mathrm{~S}^{-} 447.0587$ found 447.0736 . Anal. RP-HPLC Method A: $t \mathrm{R} 12.17 \mathrm{~min}$, purity $>99 \%$; Method B: $t \mathrm{R}$ $11.83 \mathrm{~min}$, purity $>99 \%$.

$N$ - ( 4 - ( $N$ - benzylsulphamoyl) phenyl ) - 5 - chloro- 2 methoxybenzamide (4l): White powder, yield: $62 \%$. $\mathrm{mp}: 172-174^{\circ} \mathrm{C}$. ${ }^{1} \mathrm{H}-\mathrm{NMR}\left(\mathrm{CDCl}_{3}\right): \delta 4.34\left(\mathrm{~s}, 3 \mathrm{H}, \mathrm{CH}_{3}\right), 4.40\left(\mathrm{~d}, 2 \mathrm{H}, J=6.2 \mathrm{~Hz}, \mathrm{CH}_{2}\right), 4.85$ $(\mathrm{t}, 1 \mathrm{H}, J=7.4 \mathrm{~Hz}, \mathrm{NH}), 7.27$ (d, $1 \mathrm{H}, J=8.9 \mathrm{~Hz}, \mathrm{Ar}-\mathrm{H}), 7.46(\mathrm{~d}, 2 \mathrm{H}, J=8.2$ $\mathrm{Hz}, \mathrm{Ar}-\mathrm{H}), 7.52(\mathrm{t}, 1 \mathrm{H}, J=7.4 \mathrm{~Hz}, \mathrm{Ar}-\mathrm{H}), 7.54(\mathrm{t}, 2 \mathrm{H}, J=7.4 \mathrm{~Hz}, \mathrm{Ar}-\mathrm{H})$, $7.74(\mathrm{dd}, 1 \mathrm{H}, J=8.8$ and $2.7 \mathrm{~Hz}, \mathrm{Ar}-\mathrm{H}), 8.07(\mathrm{~d}, 2 \mathrm{H}, J=8.8 \mathrm{~Hz}, \mathrm{Ar}-\mathrm{H}), 8.13$ (d, $2 \mathrm{H}, J=8.8 \mathrm{~Hz}, \mathrm{Ar}-\mathrm{H}), 8.51$ (d, $1 \mathrm{H}, J=2.7 \mathrm{~Hz}, \mathrm{Ar}-\mathrm{H}$ ), 10.23 (br s, $1 \mathrm{H}$, $\mathrm{NH}) .{ }^{13} \mathrm{C}-\mathrm{NMR}\left(\mathrm{CDCl}_{3}\right): \delta 47.5,56.9,113.3,120.4,122.7,127.6,128.1$, 128.2, 128.7, 128.9, 132.5, 133.6, 134.9, 136.3, 142.3, 155.9, 162.4. MS (ESI) $\mathrm{m} / z$ [M-H] $]^{-}$calcd. for $\mathrm{C}_{21} \mathrm{H}_{18} \mathrm{ClN}_{2} \mathrm{O}_{4} \mathrm{~S}^{-} 429.0681$ found 429.0740 . Anal. RP-HPLC Method A: $t \mathrm{R} 12.07$ min, purity $>99 \%$; Method B: $t \mathrm{R}$ $11.64 \mathrm{~min}$, purity $>99 \%$.

5 -chloro- $N$ - (4- $(N$-isopropylsulphamoyl) phenyl) - 2 methoxybenzamide $(4 \mathrm{~m})$ : White powder, yield: $93 \%$. mp: $185-187^{\circ} \mathrm{C}$. ${ }^{1} \mathrm{H}-\mathrm{NMR}\left(\mathrm{CDCl}_{3}\right): \delta 1.09\left(\mathrm{~d}, J=6.6 \mathrm{~Hz}, 6 \mathrm{H}, 2 \mathrm{CH}_{3}\right), 3.44-3.51(\mathrm{~m}, 1 \mathrm{H}$, $\mathrm{CH}), 4.09\left(\mathrm{~s}, 3 \mathrm{H}, \mathrm{CH}_{3}\right), 6.52(\mathrm{br} \mathrm{d}, 1 \mathrm{H}, J=7.3 \mathrm{~Hz}, \mathrm{NH}), 6.99(\mathrm{~d}, 1 \mathrm{H}, J=8.9$ $\mathrm{Hz}, \mathrm{Ar}-\mathrm{H}$ ), 7.47 (dd, $1 \mathrm{H}, J=8.8$ and $2.7 \mathrm{~Hz}, \mathrm{Ar}-\mathrm{H}), 7.80$ (d, $2 \mathrm{H}, J=8.8$ $\mathrm{Hz}, \mathrm{Ar}-\mathrm{H}), 7.87$ (d, 2H, J=8.8 Hz, Ar-H), 8.24 (d, $1 \mathrm{H}, J=2.7 \mathrm{~Hz}, \mathrm{Ar}-\mathrm{H})$, 9.96 (br s, $1 \mathrm{H}, \mathrm{NH}) .{ }^{13} \mathrm{C}-\mathrm{NMR}\left(\mathrm{CDCl}_{3}\right): \delta 24.1,46.3,57.0,113.4,120.3$, $122.7,127.6,128.5,132.5,133.7,136.3,142.1,156.0,162.4$. MS (ESI) $\mathrm{m} / z[\mathrm{M}+\mathrm{H}]^{+}$calcd. for $\mathrm{C}_{17} \mathrm{H}_{20} \mathrm{ClN}_{2} \mathrm{O}_{4} \mathrm{~S}^{+} 383.0827$ found 383.0748. Anal. RP-HPLC Method A: $t$ R 11.77 min, purity $>99 \%$; Method B: $t \mathrm{R} 11.28$ $\min$, purity $>99 \%$.

5-chloro-2-methoxy- $N$-(4-( $N$-propylsulphamoyl)phenyl) benzamide (4n): White powder, yield: $92 \%$. mp: $182-184^{\circ} \mathrm{C} .{ }^{1} \mathrm{H}-\mathrm{NMR}$ $\left(\mathrm{CDCl}_{3}\right): \delta 0.9\left(\mathrm{t}, J=7.4 \mathrm{~Hz}, 3 \mathrm{H}, \mathrm{CH}_{3}\right), 1.50-1.60\left(\mathrm{~m}, 2 \mathrm{H}, \mathrm{CH}_{2}\right), 2.95(\mathrm{q}$, $\left.J=6.7 \mathrm{~Hz}, 2 \mathrm{H}, \mathrm{CH}_{2}\right), 4.11\left(\mathrm{~s}, 3 \mathrm{H}, \mathrm{CH}_{3}\right), 4.34-4.36$ (br m, $\left.1 \mathrm{H}, \mathrm{NH}\right), 7.03$ (d, $1 \mathrm{H}, J=8.9 \mathrm{~Hz}, \mathrm{Ar}-\mathrm{H}), 7.50(\mathrm{dd}, 1 \mathrm{H}, J=8.8$ and $2.7 \mathrm{~Hz}, \mathrm{Ar}-\mathrm{H}), 7.83$ (d, $2 \mathrm{H}, J=8.9 \mathrm{~Hz}, \mathrm{Ar}-\mathrm{H}$ ), 7.87 (d, $2 \mathrm{H}, J=8.9 \mathrm{~Hz}, \mathrm{Ar}-\mathrm{H}), 8.27$ (d, $1 \mathrm{H}$, $J=2.7 \mathrm{~Hz}, \mathrm{Ar}-\mathrm{H}), 9.98$ (br s, $1 \mathrm{H}, \mathrm{NH}) .{ }^{13} \mathrm{C}-\mathrm{NMR}\left(\mathrm{CDCl}_{3}\right): \delta 11.3,23.2$, 45.2, 57.0, 113.4, 120.4, 122.9, 127.7, 128.6, 132.6, 133.7, 135.2, 142.1, 155.9, 162.4. MS (ESI) $\mathrm{m} / z[\mathrm{M}+\mathrm{H}]^{+}$calcd. for $\mathrm{C}_{17} \mathrm{H}_{20} \mathrm{ClN}_{2} \mathrm{O}_{4} \mathrm{~S}^{+} 383.0827$ found 383.0553. Anal. RP-HPLC Method A: $t \mathrm{R} 12.81 \mathrm{~min}$, purity $>99 \%$; Method B: $t \mathrm{R} 11.34$ min, purity $>99 \%$.

5-chloro- $N$-(4-( $N$-(3-(dimethylamino)propyl) sulphamoyl) phenyl)-2-methoxybenzamide (4o): White crystalline solid, yield: 46\%. mp: $224-226^{\circ} \mathrm{C} .{ }^{1} \mathrm{H}-\mathrm{NMR}$ (DMSO- $\left.d_{6}\right): \delta 1.76-1.81\left(\mathrm{~m}, 2 \mathrm{H}, \mathrm{CH}_{2}\right.$ ), $2.70\left(\mathrm{~s}, 6 \mathrm{H}, 2 \mathrm{CH}_{3}\right), 2.78\left(\mathrm{q}, J=6.7 \mathrm{~Hz}, 2 \mathrm{H}, \mathrm{CH}_{2}\right), 3.02(\mathrm{t}, J=6.7 \mathrm{~Hz}, 2 \mathrm{H}$, $\left.\mathrm{CH}_{2}\right), 3.87$ (s, $\left.3 \mathrm{H}, \mathrm{CH}_{3}\right), 7.23(\mathrm{~d}, 1 \mathrm{H}, J=8.9 \mathrm{~Hz}, \mathrm{Ar}-\mathrm{H}), 7.57$ (dd, $1 \mathrm{H}$, $J=8.8$ and $2.7 \mathrm{~Hz}, \mathrm{Ar}-\mathrm{H}), 7.60(\mathrm{~d}, 1 \mathrm{H}, J=8.9 \mathrm{~Hz}, \mathrm{Ar}-\mathrm{H}), 7.78(\mathrm{~d}, 2 \mathrm{H}, J=8.9$ $\mathrm{Hz}, \mathrm{Ar}-\mathrm{H}), 7.92$ (d, 2H, J=8.9 Hz, Ar-H), 10.14 (br s, 1H, NH), 10.60 (br s, $1 \mathrm{H}, \mathrm{NH}) .{ }^{13} \mathrm{C}-\mathrm{NMR}\left(\mathrm{DMSO}-d_{6}\right): \delta 24.2,42.1,54.3,56.4,114.1,119.6$, $124.3,126.2,126.7,127.8,128.7,131.6,134.5,142.4,155.3,163.9 . \mathrm{MS}$ (ESI) $\mathrm{m} / z[\mathrm{M}+\mathrm{H}]^{+}$calcd. for $\mathrm{C}_{19} \mathrm{H}_{25} \mathrm{ClN}_{3} \mathrm{O}_{4} \mathrm{~S}^{+} 426.1249$ found 426.1424 . Anal. RP-HPLC Method A: $t \mathrm{R} 10.01$ min, purity $>95 \%$; Method B: $t \mathrm{R}$ $8.61 \mathrm{~min}$, purity $>95 \%$.

5-chloro- $N$ - (4-( $N$-cyclohexylsulphamoyl) phenyl) - 2 methoxybenzamide (4p): White powder, yield: $56 \%$. mp: $170-172^{\circ} \mathrm{C}$. ${ }^{1} \mathrm{H}-\mathrm{NMR}\left(\mathrm{CDCl}_{3}\right): \delta 1.05-1.24\left(\mathrm{~m}, 6 \mathrm{H}, 3 \mathrm{CH}_{2}\right), 1.48-1.50(\mathrm{~m}, 1 \mathrm{H}, \mathrm{CH})$, 1.60-1.63 (m, 2H, $\left.\mathrm{CH}_{2}\right), 1.73-1.75\left(\mathrm{~m}, 2 \mathrm{H}, \mathrm{CH}_{2}\right), 4.06\left(\mathrm{~s}, 3 \mathrm{H}, \mathrm{CH}_{3}\right), 4.83$ 
(br d, $1 \mathrm{H}, J=7.2 \mathrm{~Hz}, \mathrm{NH}), 6.98$ (d, 1H, J=8.9 Hz, Ar-H), 7.43 (dd, $1 \mathrm{H}$, $J=8.8$ and $2.7 \mathrm{~Hz}, \mathrm{Ar}-\mathrm{H}), 7.78(\mathrm{~d}, 2 \mathrm{H}, J=8.8 \mathrm{~Hz}, \mathrm{Ar}-\mathrm{H}), 7.84(\mathrm{~d}, 2 \mathrm{H}, J=8.8$ $\mathrm{Hz}, \mathrm{Ar}-\mathrm{H}$ ), 8.19 (d, 1H, J=2.7 Hz, Ar-H), 9.96 (br s, 1H, NH). ${ }^{13} \mathrm{C}-\mathrm{NMR}$ $\left(\mathrm{CDCl}_{3}\right): \delta 24.8,25.3,34.1,52.8,57.0,113.4,120.27,122.7,127.4,128.3$, $132.3,133.5,136.6,141.9,155.9,162.4$. MS (ESI) $\mathrm{m} / z[\mathrm{M}+\mathrm{H}]^{+}$calcd. for $\mathrm{C}_{20} \mathrm{H}_{24} \mathrm{ClN}_{2} \mathrm{O}_{4} \mathrm{~S}^{+} 423.1140$ found 423.1053. Anal. RP-HPLC Method A: $t \mathrm{R} 12.33 \mathrm{~min}$, purity $>99 \%$; Method B: $t \mathrm{R} 12.01 \mathrm{~min}$, purity $>99 \%$.

5-chloro-2-methoxy- $N$-(4-(morpholinosulphonyl)phenyl) benzamide (4q): White crystalline solid, yield: $78 \%$. mp: $238-240^{\circ} \mathrm{C}$. ${ }^{1} \mathrm{H}-\mathrm{NMR}\left(\mathrm{CDCl}_{3}\right): \delta 3.02\left(\mathrm{t}, J=9.2 \mathrm{~Hz}, 4 \mathrm{H}, 2 \mathrm{CH}_{2}\right), 3.77(\mathrm{t}, J=9.2 \mathrm{~Hz}, 4 \mathrm{H}$, $\left.2 \mathrm{CH}_{2}\right), 4.11\left(\mathrm{~s}, 3 \mathrm{H}, \mathrm{CH}_{3}\right), 7.03(\mathrm{~d}, 1 \mathrm{H}, J=8.8 \mathrm{~Hz}, \mathrm{Ar}-\mathrm{H}), 7.50(\mathrm{dd}, 1 \mathrm{H}$, $J=8.8$ and $2.7 \mathrm{~Hz}, \mathrm{Ar}-\mathrm{H}), 7.78(\mathrm{~d}, 2 \mathrm{H}, J=8.8 \mathrm{~Hz}, \mathrm{Ar}-\mathrm{H}), 7.87(\mathrm{~d}, 2 \mathrm{H}$, $J=8.8 \mathrm{~Hz}, \mathrm{Ar}-\mathrm{H}), 8.26$ (d, $1 \mathrm{H}, J=2.7 \mathrm{~Hz}, \mathrm{Ar}-\mathrm{H}), 10.00$ (br s, $1 \mathrm{H}, \mathrm{NH})$. ${ }^{13} \mathrm{C}-\mathrm{NMR}\left(\mathrm{CDCl}_{3}\right): \delta 46.2,57.1,66.3,113.4,120.4,122.7,127.6,129.4$, $130.2,132.5,133.7,142.6,156.0,162.5$. MS (ESI) $\mathrm{m} / z[\mathrm{M}+\mathrm{H}]^{+}$calcd. $\mathrm{C}_{18} \mathrm{H}_{20} \mathrm{ClN}_{2} \mathrm{O}_{5} \mathrm{~S}^{+} 411.0776$ found 411.0483. Anal. RP-HPLC Method A: $t$ R 11.69 min, purity $>99 \%$; Method B: $t$ R $11.21 \mathrm{~min}$, purity $>99 \%$.

5-chloro- $\mathrm{N}$-(4-((4-hydroxypiperidin-1-yl)sulponyl)phenyl)-2methoxybenzamide (4r): White crystalline solid, yield: 56\%. mp: 220 $222^{\circ} \mathrm{C} .{ }^{1} \mathrm{H}-\mathrm{NMR}\left(\mathrm{CDCl}_{3}\right): \delta 1.05-1.12(\mathrm{~m}, 1 \mathrm{H}, \mathrm{CH}), 1.40-1.49(\mathrm{~m}, 1 \mathrm{H}$, $\mathrm{CH}), 1.69-1.72\left(\mathrm{~m}, 2 \mathrm{H}, \mathrm{CH}_{2}\right), 2.09-2.13(\mathrm{~m}, 1 \mathrm{H}, \mathrm{CH}), 2.29-2.33(\mathrm{~m}, 1 \mathrm{H}$, $\mathrm{CH}), 3.27-3.29(\mathrm{~m}, 1 \mathrm{H}, \mathrm{CH}), 3.39-3.41(\mathrm{~m}, 1 \mathrm{H}, \mathrm{CH}), 3.50-3.55(\mathrm{~m}, 1 \mathrm{H}$, $\mathrm{CH}), 3.87\left(\mathrm{~s}, 3 \mathrm{H}, \mathrm{CH}_{3}\right), 4.99(\mathrm{~d}, 1 \mathrm{H}, J=4.65 \mathrm{~Hz}, \mathrm{OH}), 7.22(\mathrm{~d}, 1 \mathrm{H}, J=8.9$ $\mathrm{Hz}, \mathrm{Ar}-\mathrm{H}), 7.57$ (dd, $1 \mathrm{H}, J=8.8$ and $2.7 \mathrm{~Hz}, \mathrm{Ar}-\mathrm{H}), 7.60(\mathrm{~d}, 1 \mathrm{H}, J=2.7$ $\mathrm{Hz}, \operatorname{Ar}-\mathrm{H}), 7.71$ (d, 2H, J=8.7 Hz, Ar-H), 7.96 (d, 2H, J=8.7 Hz, Ar$\mathrm{H}), 10.63$ (br s, $1 \mathrm{H}, \mathrm{NH}) .{ }^{13} \mathrm{C}-\mathrm{NMR}\left(\mathrm{CDCl}_{3}\right): \delta 22.3,32.0,45.9,52.7$, 56.4, 65.0, 114.1, 119.6, 124.3, 126.9, 128.7, 128.8, 129.8, 131.6, 143.0, 155.4, 164.1. MS (ESI) $\mathrm{m} / z[\mathrm{M}+\mathrm{H}]^{+}$calcd. for $\mathrm{C}_{19} \mathrm{H}_{22} \mathrm{ClN}_{2} \mathrm{O}_{5} \mathrm{~S}^{+} 425.0932$ found 425.0949. Anal. RP-HPLC Method A: $t \mathrm{R} 11.83 \mathrm{~min}$, purity $>99 \%$; Method B: $t \mathrm{R} 10.32 \mathrm{~min}$, purity $>99 \%$.

5-chloro-2-methoxy- $\mathrm{N}$-(4-((4-methylpiperazin-1-yl)sulphonyl) phenyl)benzamide (4s): White powder, yield: $66 \%, \mathrm{mp}: 180-182^{\circ} \mathrm{C}$. ${ }^{1} \mathrm{H}-\mathrm{NMR}\left(\mathrm{CDCl}_{3}\right): \delta 2.40\left(\mathrm{~s}, 3 \mathrm{H}, \mathrm{CH}_{3}\right), 2.63$ (br s, $\left.4 \mathrm{H}, 2 \mathrm{CH}_{2}\right), 3.18$ (br s, $\left.4 \mathrm{H}, 2 \mathrm{CH}_{2}\right), 4.19\left(\mathrm{~s}, 3 \mathrm{H}, \mathrm{CH}_{3}\right), 7.10(\mathrm{~d}, 1 \mathrm{H}, J=8.9 \mathrm{~Hz}, \mathrm{Ar}-\mathrm{H}), 7.57$ (dd, $1 \mathrm{H}, J=8.8$ and $2.7 \mathrm{~Hz}, \mathrm{Ar}-\mathrm{H}), 7.83(\mathrm{~d}, 2 \mathrm{H}, J=8.8 \mathrm{~Hz}, \mathrm{Ar}-\mathrm{H}), 7.92(\mathrm{~d}$, $2 \mathrm{H}, J=8.8 \mathrm{~Hz}, \mathrm{Ar}-\mathrm{H}$ ), 8.33 (d, $1 \mathrm{H}, J=2.7 \mathrm{~Hz}, \mathrm{Ar}-\mathrm{H}), 10.06$ (br s, $1 \mathrm{H}$, $\mathrm{NH}) .{ }^{13} \mathrm{C}-\mathrm{NMR}\left(\mathrm{CDCl}_{3}\right): \delta 45.8,46.0,54.2,57.1,113.4,120.2,122.7$, $127.6,129.3,130.4,132.5,133.7,142.5,155.9,162.4$. MS (ESI) $\mathrm{m} / \mathrm{z}$ $[\mathrm{M}+\mathrm{H}]^{+}$calcd. for $\mathrm{C}_{19} \mathrm{H}_{23} \mathrm{ClN}_{3} \mathrm{O}_{4} \mathrm{~S}^{+} 424.1092$ found 424.0984. Anal. RPHPLC Method A: $t \mathrm{R} 10.10 \mathrm{~min}$, purity>99\%; Method B: $t \mathrm{R} 8.6 \mathrm{~min}$, purity $>99 \%$.

$\mathrm{N}$-(4-((4-acetylpiperazin-1-yl)sulphonyl)phenyl)-5-chloro-2methoxybenzamide (4t): White powder, yield: $52 \%$. mp: $170-172^{\circ} \mathrm{C}$. ${ }^{1} \mathrm{H}-\mathrm{NMR}\left(\mathrm{CDCl}_{3}\right): \delta 2.04\left(\mathrm{~s}, 3 \mathrm{H}, \mathrm{CH}_{3}\right), 3.00\left(\mathrm{t}, 2 \mathrm{H}, \mathrm{J}=9.7, \mathrm{CH}_{2}\right), 3.04(\mathrm{t}$, $\left.2 \mathrm{H}, J=9.5, \mathrm{CH}_{2}\right), 3.56\left(\mathrm{t}, 2 \mathrm{H}, J=9.7, \mathrm{CH}_{2}\right), 3.71\left(\mathrm{t}, 2 \mathrm{H}, J=9.5, \mathrm{CH}_{2}\right), 4.10$ $\left(\mathrm{s}, 3 \mathrm{H}, \mathrm{CH}_{3}\right), 7.02(\mathrm{~d}, 1 \mathrm{H}, J=8.8 \mathrm{~Hz}, \mathrm{Ar}-\mathrm{H}), 7.49(\mathrm{dd}, 1 \mathrm{H}, J=8.8$ and 2.7 $\mathrm{Hz}, \mathrm{Ar}-\mathrm{H}), 7.74(\mathrm{~d}, 2 \mathrm{H}, J=8.7 \mathrm{~Hz}, \mathrm{Ar}-\mathrm{H}), 7.86(\mathrm{~d}, 2 \mathrm{H}, J=8.7 \mathrm{~Hz}, \mathrm{Ar}-\mathrm{H})$, $8.24(\mathrm{~d}, 1 \mathrm{H}, J=2.7 \mathrm{~Hz}, \mathrm{Ar}-\mathrm{H}), 10.00$ (br s, $1 \mathrm{H}, \mathrm{NH}) .{ }^{13} \mathrm{C}-\mathrm{NMR}\left(\mathrm{CDCl}_{3}\right)$ : $\delta 21.4,40.8,45.8,46.0,46.3,57.0,113.4,120.4,122.6,127.6,129.2,130.1$, $132.4,133.7,142.7,155.9,162.5,169.1$. MS (ESI) $\mathrm{m} / z[\mathrm{M}+\mathrm{H}]^{+}$calcd. for $\mathrm{C}_{20} \mathrm{H}_{23} \mathrm{ClN}_{3} \mathrm{O}_{5} \mathrm{~S}^{+} 452.1041$ found 452.0593. Anal. RP-HPLC Method A: $t \mathrm{R} 11.37 \mathrm{~min}$, purity $>99 \%$; Method B: $t \mathrm{R} 10.54 \mathrm{~min}$, purity $>99 \%$.

\section{Biology}

Cell culture: Human pancreatic epithelioid carcinoma cell line (PANC-1), pancreatic adenocarcinoma cell line (PANC 10.05) and pancreatic carcinoma cell line (Mia $\mathrm{PaCa}-2)$ were purchased from American Type Culture Collection (ATCC) (Manassas, VA, USA). Epithelial ovarian cancer cell line (A2780) was purchased from the European Collection of Cell Culture (ECACC). Biphenotypic B myelomonocytic leukaemia cell line (MV-4-11), acute myeloblastic leukaemia cell line (Kasumi-1), acute myeloid leukaemia cell line (PL21), acute myelogenous leukaemia cell line (KG-1) and histiocytic lymphoma cell line (U-937) were kindly provided by Prof. R. D’Andrea (University of South Australia). Epithelial colon cancer cell line (HCT116) was obtained from the cell bank at the Centre for Drug Discovery and Development, University of South Australia. The cell lines were cultured in RPMI-1640 with 10\% fetal bovine serum (FBS).

Cell viability assay: The cell viability experiments of suspension cell lines i.e. MV-4-11, Kasumi-1, PL-21, KG-1 and U-937 were performed with resazurin (Sigma-Aldrich) assay as previously described [25]. Cells were seeded into 96-well plates and incubated at $37^{\circ} \mathrm{C}, 5 \% \mathrm{CO}_{2}$ overnight. Each compound was diluted from a 2 or 10 $\mathrm{mM}$ stock solution to prepare a five-fold dilution series in $100 \mu \mathrm{L}$ of cell medium, added to cells (in triplicates), and incubated at $37^{\circ} \mathrm{C}, 5 \%$ $\mathrm{CO}_{2}$ for $72 \mathrm{~h}$. Resazurin (Sigma-Aldrich) was made up as a stock of 0.1 $\mathrm{mg} / \mathrm{mL}$ in cell medium and filter-sterilised. The resazurin solution was added at $20 \mu \mathrm{L} /$ well and incubated in the dark at $37^{\circ} \mathrm{C}, 5 \% \mathrm{CO}$, for $4 \mathrm{~h}$. The plate was left at room temperature for 10-15 min, and absorbance was measured at $585 \mathrm{~nm}$ using an EnVision multi-label plate reader (PerkinElmer, Buckinghamshire, UK).

On the other hand, the cell viability experiments of non-suspension cell lines i.e. A2780, HCT-116, PANC-1, PANC 10.05 and Mia PaCa2 were carried out with MTT (Sigma-Aldrich) assays as described previously [26]. In short, cells were seeded into 96-well plates according to doubling time and incubated overnight at $37^{\circ} \mathrm{C}$. Test compounds were made up in DMSO, and a 3 -fold dilution series was prepared in $100 \mu \mathrm{L}$ of cell medium, added to cells (in triplicates), and incubated for 72 or $96 \mathrm{~h}$ at $37^{\circ} \mathrm{C}$. MTT was made up as a stock of $5 \mathrm{mg} / \mathrm{mL}$ in cell medium, and the solution was filter-sterilised. Medium was removed from cells followed by a wash with $200 \mu \mathrm{L} /$ well of PBS. MTT solution was then added at $20 \mu \mathrm{L} /$ well and incubated in the dark at $37^{\circ} \mathrm{C}$ for 4 h. MTT solution was removed and cells were again washed with 200 $\mu \mathrm{L}$ of PBS. MTT dye was solubilised with $200 \mu \mathrm{L} /$ well of DMSO with agitation. Absorbance was read at $540 \mathrm{~nm}$. Compound concentrations required to inhibit $50 \%$ of cell growth $\left(\mathrm{GI}_{50}\right)$ were calculated using nonlinear regression analysis.

Cell cycle and apoptosis detection: The cell cycle experiment and apoptosis detection for MiaPaCa-2 cells were tested with flow cytometry, as described previously [25]. Briefly, the MiaPaCa-2 cells were seeded at $8 \times 10^{4}$ and incubated overnight at $37^{\circ} \mathrm{C}, 5 \% \mathrm{CO}_{2}$ before treatment. After treatment with the compounds, cells were trypsinised and collected for staining. For cell cycle experiments, collected cells were fixed with $70 \%$ ethanol on ice for $15 \mathrm{~min}$ and centrifuged again at $300 \mathrm{~g}$ for $5 \mathrm{~min}$ to recollect the cells. The collected pellets were incubated with propidium iodide (PI) staining solution $(50 \mu \mathrm{g} / \mathrm{mL}$ PI, $0.1 \mathrm{mg} / \mathrm{mL}$ RNase A, $0.05 \%$ Triton X-100) at room temperature for $1 \mathrm{~h}$ and analysed by Gallios flow cytometry with FACS (Beckman Coulter). The apoptosis detections were performed with annexin-V/PI assay. The treated cell pellets were collected and stained with annexin-V FITC/PI commercial kit (Becton Dickinson) following the supplier's protocol. The samples were analysed by fluorescence-activated cell sorting (FACS) with Gallios flow cytometry (Beckman Coulter) within $1 \mathrm{~h}$ after staining. The data were analysed using Kaluza v1.2 (Beckman Coulter).

\section{Results and Discussion}

\section{Chemistry}

The synthetic route to 5-chloro-2-methoxy- $N$-(4sulphamoylphenyl)benzamide derivatives $4 \mathrm{a}-4 \mathrm{t}$ is outlined in Scheme 1. 5-Chloro-2-methoxybenzoic acid 1 was reacted with 
aniline using ethylchloroformate as coupling reagent in the presence of triethylamine in dichloromethane (DCM) to give 5-chloro-2methoxy- $N$-phenylbenzamide 2 in a yield of $94 \%$. Subsequently, the chlorosulphonation of amide 2 was achieved by reacting with chlorosulphonic acid affording 4-(5-chloro-2-methoxybenzamido) benzenesulphonyl chloride 3 in a yield of $87 \%$. Finally, sulphonyl chloride 3 was coupled with appropriate amines in the presence of sodium carbonate in a mixture of tetrahydrofuran (THF) and water to yield the desired 5-chloro-2-methoxy- $N$-(4-sulphamoylphenyl) benzamide derivatives $4 \mathrm{a}-4 \mathrm{t}$; in moderate to excellent yields (45-93\%).

\section{Structure-activity relationship analysis}

The anti-proliferative activity of these sulphonamide derivatives was evaluated with A2780 and HCT-116 cell lines using MTT assay. Both cell lines are frequently used as model systems for exploration of cancer pathways and for innovation of new therapeutic approaches [27]. Moreover, they are commonly used in the assessment of the antiproliferative activity of many sulphonamide compounds [27-29]. The $\mathrm{GI}_{50}$ values are summarised in Table 1. E7010, a known anti-cancer sulphonamide, was used as a positive control in the assays.

In general, ovarian cancer A2780 cells seemed more sensitive to compounds with aromatic sulphonamide substitutions, while HCT-116 cells were more sensitive to compounds with aliphatic sulphonamide groups. To put this in perspective, for compounds with aromatic sulphonamides, the nature and position of the substituents of $\mathrm{R}$ had a tangible effect on the cellular activity. Compound $4 \mathrm{j}$, i.e. $\mathrm{R}=\mathrm{NH}-$ $(p-\mathrm{F}) \mathrm{Ph}$, exhibited the most potent anti-proliferative activity with $\mathrm{GI}_{50}$ values of 29.1 and $39.3 \mu \mathrm{M}$ in A2780 and HCT-116 cells, respectively, suggesting the importance of the para-fluorine substituent for cellular activity. Further introduction of an additional methyl group at the ortho position resulting in $4 \mathrm{k}$ not only reduced the activity against A2780 but also abolished the activity against HCT-116 cells. In general, all substitutions gave less active derivatives when compared to $4 \mathrm{a}, 4 \mathrm{j}$ and $4 \mathrm{~b}$ against A2780. However, the effects of the substituents on cellular potency were not clear. For example, $4 \mathrm{~d}$, i.e. $\mathrm{R}=\mathrm{NH}-(o-\mathrm{Et}) \mathrm{Ph}$, was more cytotoxic than $4 \mathrm{e}$, i.e. $\mathrm{R}=\mathrm{NH}-(p-\mathrm{Et}) \mathrm{Ph}$, to $\mathrm{A} 2780$ cells. In contrast, $4 \mathrm{f}$ $\left(\mathrm{R}=\mathrm{NH}-\left(o-\mathrm{CF}_{3}\right) \mathrm{Ph}\right)$ was less potent than $4 \mathrm{~g}$, i.e. $\left.\mathrm{R}=\mathrm{NH}-\left(p-\mathrm{CF}_{3}\right) \mathrm{Ph}\right)$. Also, the ortho substitution led to the similar activities, although ortho$\mathrm{OCH}_{3}$ substituted derivative (4h) gave rise to the least potent compound against A2780 cells among all compounds with aromatic sulphonamide groups. In addition, spacing the phenyl ring with one methylene group halved the anti-proliferative activity against A2780 cells and abrogated the activity against HCT-116 cells (i.e. 4 a versus 41 ).

For the aliphatic sulphonamide analogues, $4 \mathrm{~m}(\mathrm{R}=\mathrm{NH}-i \mathrm{Pr})$ was more active than $4 \mathrm{n}(\mathrm{R}=\mathrm{NH}-n \mathrm{Pr})$, suggesting the importance of the branching structure for the activity. $4 \mathrm{o}$, i.e. $\mathrm{R}=\mathrm{NH}\left(\mathrm{CH}_{2}\right)_{3} \mathrm{~N}\left(\mathrm{CH}_{3}\right)_{2}$, exhibited the most potent anti-proliferative activity among all aliphatic sulphonamides.

Moreover, compounds 4q ( $\mathrm{R}=1$-morpholinyl) and $4 \mathrm{r} \quad(\mathrm{R}=p$ hydroxypipridinyl) exerted similar activity against A2780 cells, but $4 \mathrm{q}$ was more active in HCT-116 cells. Similarly, the derivatives containing $p$-methylpiperazinyl (4s) or $p$-acetylpiperazinyl group (4t) had a similar effect on A2780 cells but the former was more active against HCT-116 cells. Noticeably, the derivatives containing an aliphatic chain were more potent compared to their cyclic counterparts. Most compounds were more cytotoxic to A2780 cells than HCT-116 cells except 4o and 4q.

\section{Cell-type sensitivity}

As one of the most biological active compounds, $4 \mathrm{j}$ was selected for further evaluation of anti-proliferative activity against a panel of eight human tumour cell lines, including leukaemia MV-4-11, Kasumi-1, PL-21, KG-1, U-937 and pancreatic cancer PANC-1, PANC 10.05 and MIA PaCa-2, to investigate its cell-type selectivity. The results are summarised in Table 2.

MIA PaCa-2 cell line was shown to be most sensitive towards the treatment of $4 \mathrm{j}\left(\mathrm{GI}_{50}=1.9 \mu \mathrm{M}\right)$, whilst PANC 10.05 was the least sensitive $\left(\mathrm{GI}_{50}=83.4 \mu \mathrm{M}\right)$. Despite the fact that $4 \mathrm{j}$ exhibited a high activity in MIA $\mathrm{PaCa}-2$ over other two pancreatic cell lines (i.e. PANC-1 and PANC 10.05) the compound showed little difference in the leukaemia cells tested (i.e. MV-4-11, Kasumi-1, PL-21, KG-1 and U-937), giving $\mathrm{GI}_{50}$ values ranging from 22.7 to $37.5 \mu \mathrm{M}$. These findings agree with the previous studies that different aryl sulphonamides had variable celltype specificity [30-36], presumably due to their different cellular mechanisms of action [24].

\section{Cellular mechanism of action}

We next investigated the cellular mode of action of $4 \mathrm{j}$ in MIA PaCa2 cells. E7010 served as a positive control. To evaluate whether the anti-proliferative effect of $4 \mathrm{j}$ is a consequence of cell cycle effects, MIA $\mathrm{PaCa}-2$ cells were exposed to each compound at the concentration of $5 \mathrm{x}$ or $10 \times \mathrm{GI}_{50} \mu \mathrm{M}$ for a period of 24 hours, and the cell cycle effects were<smiles>COc1ccc(Cl)cc1C(=O)O</smiles><smiles>COc1ccc(Cl)cc1C(=O)Nc1ccccc1</smiles>

4a: $\mathrm{R}=\mathrm{NHPh}$<smiles>[R]S(=O)(=O)c1ccc(NC(=O)c2cc(Cl)ccc2OC)cc1</smiles>

4a-t

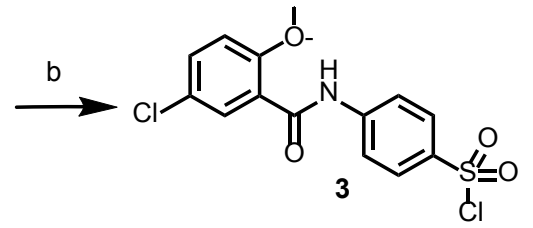

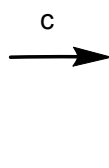

4k: $\mathrm{R}=\mathrm{NH}-(2-\mathrm{Me}-4-\mathrm{F}) \mathrm{Ph}$

4l: $\mathrm{R}=\mathrm{NHCH}_{2} \mathrm{Ph}$

4m: $\mathrm{R}=\mathrm{NH}-\mathrm{iPr}$

$4 \mathrm{n}: \mathrm{R}=\mathrm{NH}-n \mathrm{Pr}$

4o: $\mathrm{R}=\mathrm{NH}\left(\mathrm{CH}_{2}\right)_{3} \mathrm{~N}\left(\mathrm{CH}_{3}\right)_{2}$

$4 \mathbf{p}: \mathrm{R}=\mathrm{NH}$-cyclohexyl

4q: $: R=1$-morpholinyl

4r: $R=$ 4-hydroxypipridinyl

4s: $R=$ 4-methylpiperaziny

4t: $R=$ 4-acetylpiperazinyl

Scheme 1: Synthesis of 5-chloro-2-methoxy- $N$-(4-sulphamoylphenyl) benzamide derivatives (4a-t). Reagents and conditions: (a) aniline, triethylamine, ethylchloroformate, DCM, rt, 3 h, 94\%; (b) chlorosulphonic acid, neat, rt, 12 h, 87\%; (c) appropriate amine, sodium carbonate, THF/ $\mathrm{H}_{2} \mathrm{O}(2: 1)$, rt, 12 h, $45-93 \%$. 


\begin{tabular}{|c|c|c|c|}
\hline \multirow{2}{*}{ Compounds } & \multirow{2}{*}{$\mathbf{R}$} & \multicolumn{2}{|c|}{ Cytotoxicity $\mathrm{Gl}_{50}(\mu \mathrm{M})^{*}$} \\
\hline & & A2780 & НСТ-116 \\
\hline $4 a$ & NHPh & $38.7 \pm 3.7$ & $48.5 \pm 3.0$ \\
\hline $4 b$ & $\mathrm{NH}-(m-\mathrm{Me}) \mathrm{Ph}$ & $31.8 \pm 5.9$ & $>100$ \\
\hline $4 \mathrm{c}$ & $\mathrm{NH}-(p-\mathrm{Me}) \mathrm{Ph}$ & $44.6 \pm 3.1$ & $>100$ \\
\hline $4 d$ & $\mathrm{NH}-(o-\mathrm{Et}) \mathrm{Ph}$ & $42.8 \pm 4.8$ & $>100$ \\
\hline $4 e$ & $\mathrm{NH}-(p-\mathrm{Et}) \mathrm{Ph}$ & $52.1 \pm 27.3$ & $>100$ \\
\hline $4 f$ & $\mathrm{NH}-\left(\mathrm{o}-\mathrm{CF}_{3}\right) \mathrm{Ph}$ & $45.0 \pm 1.3$ & $>100$ \\
\hline $4 g$ & $\mathrm{NH}-\left(p-\mathrm{CF}_{3}\right) \mathrm{Ph}$ & $40.6 \pm 4.5$ & $>100$ \\
\hline $4 \mathrm{~h}$ & $\mathrm{NH}-(\mathrm{o}-\mathrm{MeO}) \mathrm{Ph}$ & $63.5 \pm 6.2$ & $76.8 \pm 4.7$ \\
\hline $4 i$ & $\mathrm{NH}-(p-\mathrm{MeO}) \mathrm{Ph}$ & $46.7 \pm 4.6$ & $58.1 \pm 5.6$ \\
\hline $4 j$ & $\mathrm{NH}-(p-\mathrm{F}) \mathrm{Ph}$ & $29.1 \pm 3.4$ & $39.3 \pm 2.9$ \\
\hline $4 k$ & $\mathrm{NH}-(o-\mathrm{Me}-4-\mathrm{F}) \mathrm{Ph}$ & $42.9 \pm 5.8$ & $>100$ \\
\hline 41 & $\mathrm{NHCH}_{2} \mathrm{Ph}$ & $73.9 \pm 5.5$ & $>100$ \\
\hline $4 m$ & $\mathrm{NH}-\mathrm{Pr}$ & $34.7 \pm 2.4$ & $59.2 \pm 6.9$ \\
\hline $4 n$ & $\mathrm{NH}-n \mathrm{Pr}$ & $55.5 \pm 16.7$ & $69.7 \pm 5.2$ \\
\hline 40 & $\mathrm{NH}\left(\mathrm{CH}_{2}\right)_{3} \mathrm{~N}\left(\mathrm{CH}_{3}\right)_{2}$ & $31.7 \pm 2.5$ & $24.7 \pm 3.4$ \\
\hline $4 p$ & $\mathrm{NH}$-cyclohexyl & $37.6 \pm 8.8$ & $50.1 \pm 4.9$ \\
\hline $4 q$ & 1-morpholinyl & $73.8 \pm 6.7$ & $56.4 \pm 5.8$ \\
\hline $4 r$ & $p$-hydroxypipridinyl & $68.7 \pm 22.3$ & $96.6 \pm 10.7$ \\
\hline $4 \mathrm{~s}$ & p-methylpiperazinyl & $45.9 \pm 10.7$ & $61.6 \pm 8.5$ \\
\hline $4 \mathrm{t}$ & $p$-acetylpiperazinyl & $48.9 \pm 8.2$ & $>100$ \\
\hline E7010 & - & $40.2 \pm 2.1$ & $64.4 \pm 4.3$ \\
\hline
\end{tabular}

Table 1: The structures and anti-proliferative activity of $\mathbf{4 a - t .}$

\section{Human cell line}

Origin

Biphenotypic B myelomonocytic leukaemia

Acute myeloblastic leukaemia

Acute myeloid leukaemia

Acute myelogenous leukaemia

Histiocytic lymphoma

Pancreatic epithelioid carcinoma

Pancreatic adenocarcinoma

Pancreatic carcinoma

\begin{tabular}{|l|l|}
\hline Designation & Cytotoxicity \\
\hline MV-4-11 & $\mathbf{G I}_{50} \boldsymbol{\mu M} \mathbf{\text { S.D. }}$ \\
\hline Kasumi-1 & $29.2 \pm 7.4^{*}$ \\
\hline PL-21 & $37.5 \pm 5.0^{*}$ \\
\hline KG-1 & $24.0 \pm 11.4^{*}$ \\
\hline U-937 & $26.4 \pm 10.1^{*}$ \\
\hline PANC-1 & $22.7 \pm 9.9^{*}$ \\
\hline PANC 10.05 & $47.0 \pm 26.9^{* *}$ \\
\hline MIA PaCa-2 & $83.4 \pm 31.6^{* *}$ \\
\hline
\end{tabular}

${ }^{*} \mathrm{GI}_{50}$ values were determined by $72 \mathrm{~h}$ resazurin assay. ${ }^{* *} \mathrm{GI}_{50}$ values were determined by $72 \mathrm{~h}$ MTT assay. Data given are the mean \pm standard deviation derived from at least two replicates.

Table 2: Anti-proliferative activity of $\mathbf{4} \mathbf{j}$ in human cancer cell lines.

analysed by flow cytometry. As shown in Figure 1, the treatment with E7010 resulted in a substantial accumulation of MIA PaCa-2 cells at the G2/M phase (54.7 and $55.7 \%$ at 2.5 and $5 \mu \mathrm{M}$, respectively) compared to the untreated cells $(28.7 \%$ in the G2/M). This is consistent with the tubulin targeting mechanism of E7010 [36-39]. Similarly, $4 \mathrm{j}$ increased in the population of the G2/M cells $(\sim 42 \%)$ at concentrations of 10 (5 $\left.\times \mathrm{GI}_{50} \mu \mathrm{M}\right)$ and $20 \mu \mathrm{M}\left(10 \times \mathrm{GI}_{50} \mu \mathrm{M}\right)$, suggesting a similar but weaker cellular mechanism compared to E7010.

To further assess the apoptotic effect of $4 \mathrm{j}$, MIA PaCa- 2 cells were treated with $4 \mathrm{j}$ (or E7010) for 24 hours, and the cells were stained with dual annexin V-FITC and propidium iodide (annexin V-FITC/PI), and analysed by flow cytometry. As shown in Figure 2, the apoptotic cells, as indicated by annexin $\mathrm{V}^{+} / \mathrm{PI}^{-}$and annexin $\mathrm{V}^{+} / \mathrm{PI}^{+}$, increased at least $6 \%$ upon treatment with $4 \mathrm{j}$ (or E7010) at the concentration of $5 \mathrm{x}$ or 10 $\times \mathrm{GI}_{50} \mu \mathrm{M}$ when compared to the untreated cells.

\section{Conclusion}

We have identified a new series of sulphonamides. The antiproliferative activity of these compounds was evaluated against A2780 and HCT-116 tumour cell lines, and the structure-activity relationship was analysed. The lead compound $4 \mathrm{j}$ exhibited a high potency against human pancreatic cancer cell line MIA PaCa-2. Cellular mechanistic investigation suggested that the anti-tumour activity of $4 \mathrm{j}$ was a consequence of the G2/M cell cycle effects and induction of apoptosis. Although further investigation is needed in order to elucidate the exact molecular targeting mechanism, this work suggests that the $\mathrm{N}-(4-$ sulphamoylphenyl)benzamide is a highly valuable scaffold to develop anti-cancer agents.

\section{Acknowledgements}

A. M. A. thanks the Egyptian National Research Centre and the Egyptian Culture Affairs and Mission Sector for providing his studentship. 


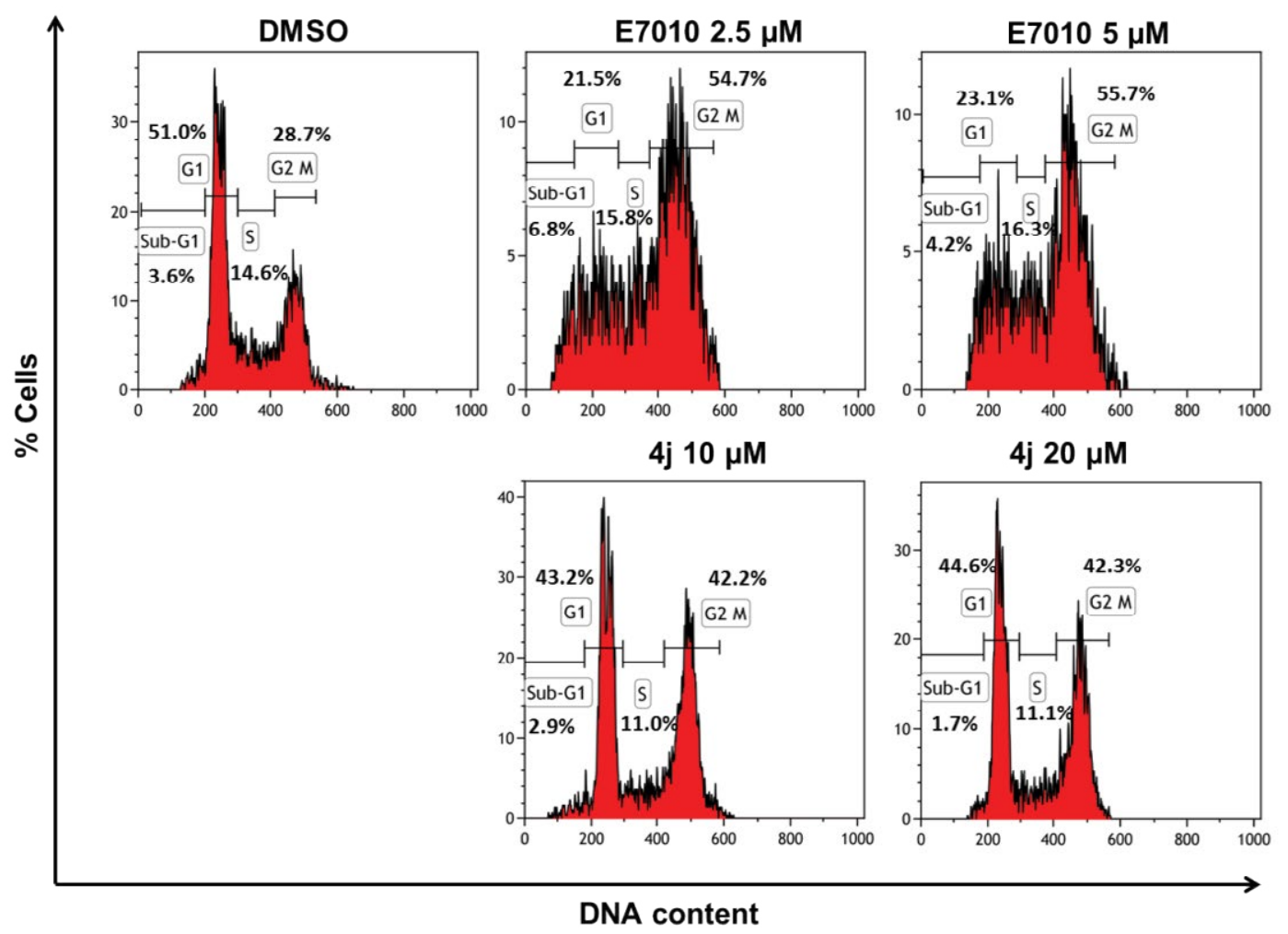

Figure 1: Cell cycle analysis of MIA PaCa-2 cells after treatment with $4 \mathrm{j}$ or E7010 for $24 \mathrm{~h}$.

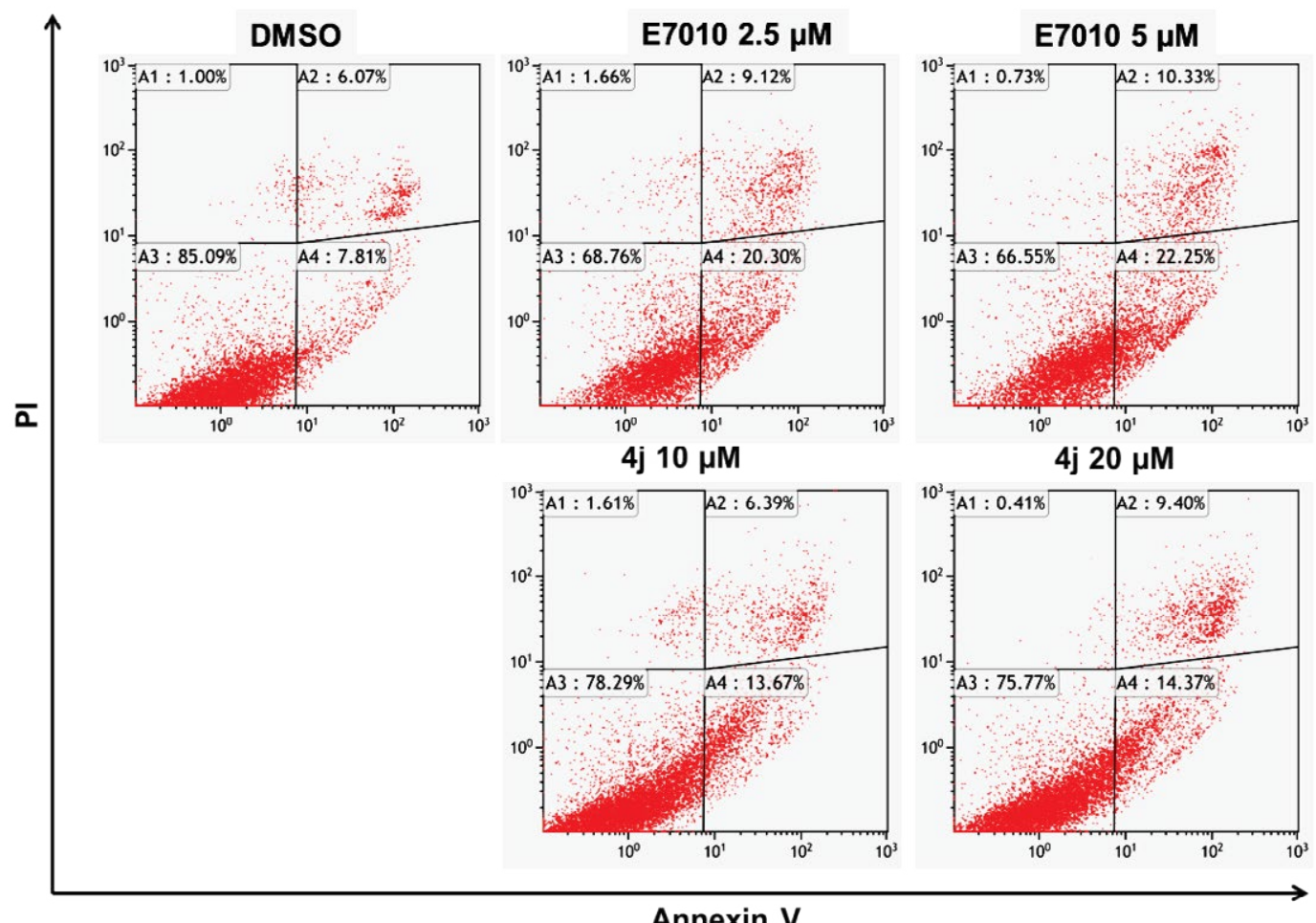

Figure 2: Cell cycle analysis of MIA PaCa-2 cells after treatment with $4 \mathbf{j}$ or E7010 for $24 \mathrm{~h}$. 
Citation: Abdelaziz AM, Yu M, Li P, Zhong L, Singab ANB, et al. (2015) Synthesis and Evaluation of 5-Chloro-2-Methoxy-N-(4-Sulphamoylphenyl) Benzamide Derivatives as Anti-cancer Agents. Med chem 5: 253-260. doi:10.4172/2161-0444.1000272

\section{References}

1. Drews J (2000) Drug discovery: a historical perspective. Science 287: 1960-1964.

2. Supuran CT, Conroy CW, Maren TH (1996) Carbonic anhydrase inhibitors: Synthesis and inhibitory properties of ,3,4-thiadiazole-2,5-bissulphonamide. Eur J Med Chem 3: 843-846.

3. Boyd AE (1988) Sulfonylurea receptors, ion channels, and fruit flies. Diabetes 37: $847-850$

4. Wouters J, Michaux C, Durant F, Dogne JM, Delarge J, et al. (2000) Isosterism among analogues of torasemide: conformational, electronic and lipophilic properties. Eur J Med Chem 35: 923-929.

5. Supuran CT, Scozzafava A (2001) Carbonic anhydrase inhibitors, Current Medicinal Chemistry-Immunology. Endocrine \& Metabolic Agents 61-97.

6. Supuran CT, Scozzafava A, Casini A (2003) Carbonic anhydrase inhibitors. Med Res Rev 23: 146-189.

7. Supuran CT, Casini A, Scozzafava A (2003) Protease inhibitors of the sulfonamide type: anticancer, antiinflammatory, and antiviral agents. Med Res Rev 23: 535-558.

8. Yoshino H, Ueda N, Niijima J, Sugumi H, Kotake $Y$, et al. (1992) Nove sulfonamides as potential, systemically active antitumor agents. J Med Chem 35: 2496-2497.

9. Banerjee M, Poddar A, Mitra G, Surolia A, Owa T, et al. (2005) Sulphonamide drugs binding to the colchicine site of tubulin: thermodynamic analysis of the drug-tubulin interactions by isothermal titration calorimetry. J Med Chem 48 : 547-555.

10. Mohan R, Banerjee M, Ray A, Manna T, Wilson L, et al. (2006) Antimitotic sulphonamides inhibit microtubule assembly dynamics and cancer cell proliferation. Biochemistry 45: 5440-5449.

11. Skiles JW, Gonnella NC, Jeng AY (2004) The design, structure, and clinical update of small molecular weight matrix metalloproteinase inhibitors. Curr Med Chem 1: 2911-2977.

12. Hu L, Li ZR, Wang YM, Wu Y, Jiang JD, et al. (2007) Novel pyridinyl and pyrimidinylcarbazole sulfonamides as antiproliferative agents. Bioorg Med Chem Lett 17: 1193-1196.

13. Abbate F, Casini A, Owa T, Scozzafava A, Supuran CT (2004) Carbonic anhydrase inhibitors: E7070, a sulphonamide anticancer agent, potently inhibits cytosolic isozymes I and II, and transmembrane, tumor-associated isozyme IX Bioorg Med Chem Lett 14: 217-223.

14. Carta F, Scozzafava A, Supuran CT (2012) Sulfonamides: a patent review (2008 - 2012). Expert Opin Ther Pat 22: 747-758.

15. Bukowski RM, Yasothan U, Kirkpatrick P (2010) Pazopanib. Nat Rev Drug Discov 9: 17-18.

16. Ajeet A, Tripathi L, Kumar A (2014) Synthesis, Spectral Characterization, Docking Studies and QSAR Screening of 4-amino-benzenesulphonamides/Nacetyl 4-amino-benzenesulphonamide Derivatives as Antimicrobial Agents. Journal of Pharmacy and Nutrition Sciences 4: 135-153.

17. Nielsen FE, Jacobsen P, Worsaae A, Arkhammar PO, Wahl P, et al. (2004) 2-(4-Methoxyphenoxy)-5-nitro-N-(4-sulfamoylphenyl)benzamide activates Kir6.2/SUR1 K(ATP) channels. Bioorg Med Chem Lett 14: 5727-5730.

18. Khanfar MA, Quinti L, Wang H, Choi SH, Kazantsev AG, et al. (2014) Development and characterization of 3-(benzylsulfonamido)benzamides as potent and selective SIRT2 inhibitors. Eur J Med Chem 76: 414-426.

19. Wang P, Liu C, Sanches T, Zhong Y, Liu B, et al. (2009) Design and synthesis of novel nitrogen-containing polyhydroxylated aromatics as HIV-1 integrase inhibitors from caffeic acid phenethyl ester. Bioorg Med Chem Lett 19: 4574 4578.

20. Domagala JM, Bader JP, Gogliotti RD, Sanchez JP, Stier MA, et al. (1997) A new class of anti-HIV-1 agents targeted toward the nucleocapsid protein NCp7: the 2,2'-dithiobisbenzamides. Bioorg Med Chem 5: 569-579.

21. Singh J, Shaik B, Singh S, Agrawal VK, Khadikar PV, et al. (2008) Comparative QSAR study on para-substituted aromatic sulphonamides as CAll inhibitors: information versus topological (distance-based and connectivity) indices. Chem Biol Drug Des 7: 244-259.

22. Brands M, Erguden JK, Hashimoto K, Heimbach D, Krahn T, et al. (2006) Selective indole-based ECE inhibitors: synthesis and pharmacological evaluation. Chem Med Chem 1: 96-105.
23. Melagraki G, Afantitis A, Sarimveis $H$, Igglessi-Markopoulou O, Supuran CT (2006) QSAR study on para-substituted aromatic sulphonamides as carbonic anhydrase II inhibitors using topological information indices. Bioorg Med Chem 14: 1108-1114.

24. Al-Said MS, Ghorab MM, Al-Qasoumi SI, El-Hossary EM, Noaman E (2010) Synthesis and in vitro anticancer screening of some novel 4-[2-amino-3-cyano4-substituted-5,6,7,8-tetrahydroquinolin-1-(4H)-yl]benzenesulfonamides. Eur J Med Chem 45: 3011-3018

25. Diab S, Teo T, Kumarasiri M, Li P, Yu M, et al. (2014) Discovery of 5-(2-(phenylamino)pyrimidin-4-yl)thiazol-2(3H)-one derivatives as potent Mnk2 inhibitors: synthesis, SAR analysis and biological evaluation. Chem Med Chem 9: 962-972.

26. Wang S, Meades C, Wood G, Osnowski A, Anderson S, et al. (2004) 2-Anilino4-(thiazol-5-yl)pyrimidine CDK inhibitors: synthesis, SAR analysis, X-ray crystallography, and biological activity. J Med Chem 47: 1662-1675.

27. Lu T, Laughton CA, Wang S, Bradshaw TD (2015) In vitro antitumor mechanism of (E)-N-(2-methoxy-5-(((2,4,6-trimethoxystyryl)sulphonyl)methyl)pyridin-3-yl) methane sulphonamide. Mol Pharmacol 87: 18-30.

28. Liu X, Lam F, Shi S, Fischer PM, Wang S (2012) In vitro antitumor mechanism of a novel cyclin-dependent kinase inhibitor CDKI-83. Invest New Drugs 30 889-897.

29. Abbassi N, Chicha H, Rakib el M, Hannioui A, Alaoui M, et al. (2012) Synthesis, antiproliferative and apoptotic activities of $\mathrm{N}$-(6(4)-indazolyl)benzenesulphonamide derivatives as potential anticancer agents. Eur $\mathrm{J}$ Med Chem 57: 240-249.

30. Seo JH, Jung KH, Son MK, Yan HH, Ryu YL, et al. (2013) Anti-cancer effect of HS-345, a new tropomyosin-related kinase A inhibitor, on human pancreatic cancer. Cancer Lett 338: 271-281.

31. Wang W, Ao L, Rayburn ER, Xu H, Zhang X, et al. (2012) KCN1, a novel synthetic sulfonamide anticancer agent: in vitro and in vivo anti-pancreatic cancer activities and preclinical pharmacology. PLoS One 7: e44883.

32. Liu ZL, Tian W, Wang Y, Kuang S, Luo XM, et al. (2012) A novel sulphonamide agent, MPSP-00, exhibits potent activity against human cancer cells in vitro through disruption of microtubule. Acta Pharmacol Sin 33: 261-270.

33. Tercel M, Atwell GJ, Yang S, Ashoorzadeh A, Stevenson RJ, et al. (2011) Selective treatment of hypoxic tumor cells in vivo: phosphate pre-prodrugs of nitro analogues of the duocarmycins. Angew Chem Int Ed Engl 50: 2606-2609.

34. Haritunians T, Gueller S, O'Kelly J, llaria R, Koeffler HP (2008) Novel acyl sulphonamide LY573636-sodium: effect on hematopoietic malignant cells. Oncol Rep 20: 1237-1242.

35. Supek F, Kralj M, Marjanovic M, Suman L, Smuc T, et al. (2008) Atypical cytostatic mechanism of $\mathrm{N}$-1-sulfonylcytosine derivatives determined by in vitro screening and computational analysis. Invest New Drugs 26: 97-110.

36. Owa T, Okauchi T, Yoshimatsu K, Sugi NH, Ozawa Y, et al. (2000) A focused compound library of novel $\mathrm{N}$-(7-indolyl)benzenesulfonamides for the discovery of potent cell cycle inhibitors. Bioorg Med Chem Lett 10: 1223-1226.

37. Kamal A, Subba AVR, Vishnuvardhan MV, Srinivas Reddy T, Swapna K, et al (2015) Synthesis of 2-anilinopyridyl-triazole conjugates as antimitotic agents. Org Biomol Chem 13: 4879-4895.

38. Kim ND, Park ES, Kim YH, Moon SK, Lee SS, et al. (2010) Structure-based virtual screening of novel tubulin inhibitors and their characterization as antimitotic agents. Bioorg Med Chem 18: 7092-7100.

39. Yokoi A, Kuromitsu J, Kawai T, Nagasu T, Sugi NH, et al. (2002) Profiling nove sulfonamide antitumor agents with cell-based phenotypic screens and arraybased gene expression analysis. Mol Cancer Ther 1: 275-286. 